\title{
A SIMPLIFIED METHOD FOR NONLINEAR CYCLIC ANALYSIS OF REINFORCED CONCRETE STRUCTURES: DIRECT AND ENERGY BASED FORMULATIONS
}

By

Hao-Ze (Ryan) Deng

A thesis submitted to

the Faculty of Graduate Studies and Research

in partial fulfillment of the requirements for the degree of

Master of Applied Science

\section{Department of Civil and Environmental Engineering Carleton University, Ottawa \\ December 2005}

\author{
The Master of Applied Science in Civil Engineering \\ is a joint program with the University of Ottawa, \\ Administered by the Ottawa-Carleton Institute for Civil Engineering
}

(C) Copyright 2005

Hao-Ze (Ryan) Deng 


$\begin{array}{ll}\begin{array}{l}\text { Library and } \\ \text { Archives Canada }\end{array} & \begin{array}{l}\text { Bibliothèque et } \\ \text { Archives Canada }\end{array} \\ \begin{array}{l}\text { Published Heritage } \\ \text { Branch }\end{array} & \begin{array}{l}\text { Direction du } \\ \text { Patrimoine de l'édition }\end{array} \\ \begin{array}{l}\text { 395 Wellington Street } \\ \text { Ottawa ON K1A ON4 }\end{array} & \begin{array}{l}\text { 395, rue Wellington } \\ \text { Ottawa ON K1A ON4 } \\ \text { Canada }\end{array}\end{array}$

Your file Votre référence ISBN: 978-0-494-16455-6 Our file Notre référence ISBN: 978-0-494-16455-6

NOTICE:

The author has granted a nonexclusive license allowing Library and Archives Canada to reproduce, publish, archive, preserve, conserve, communicate to the public by telecommunication or on the Internet, loan, distribute and sell theses worldwide, for commercial or noncommercial purposes, in microform, paper, electronic and/or any other formats.

The author retains copyright ownership and moral rights in this thesis. Neither the thesis nor substantial extracts from it may be printed or otherwise reproduced without the author's permission.
AVIS:

L'auteur a accordé une licence non exclusive permettant à la Bibliothèque et Archives Canada de reproduire, publier, archiver, sauvegarder, conserver, transmettre au public par télécommunication ou par l'Internet, prêter, distribuer et vendre des thèses partout dans le monde, à des fins commerciales ou autres, sur support microforme, papier, électronique et/ou autres formats.

L'auteur conserve la propriété du droit d'auteur et des droits moraux qui protège cette thèse. $\mathrm{Ni}$ la thèse ni des extraits substantiels de celle-ci ne doivent être imprimés ou autrement reproduits sans son autorisation.
In compliance with the Canadian

Privacy Act some supporting forms may have been removed from this thesis.

While these forms may be included in the document page count, their removal does not represent any loss of content from the thesis.
Conformément à la loi canadienne sur la protection de la vie privée, quelques formulaires secondaires ont été enlevés de cette thèse.

Bien que ces formulaires aient inclus dans la pagination, il n'y aura aucun contenu manquant.

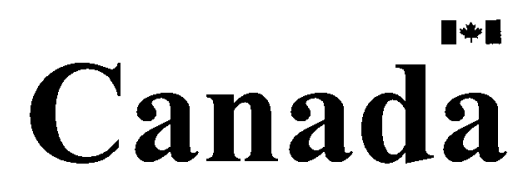




\section{ABSTRACT}

This thesis presents a simplified method based on direct and energy formulations for nonlinear analysis of reinforced concrete frame structures. In the simplified method, a reinforced concrete member is modeled by an equivalent member of homogeneous nonlinear material with a derived stress-strain relationship, which satisfies the requirement that the equivalent member has the same moment-curvature behavior as the original member. One advantage of the simplified method is its simplicity which can be easily implemented in most structural analysis computer programs with nonlinear modeling capabilities. The developed model can accurately predict the nonlinear hysteretic responses of reinforced concrete structures with frame members of arbitrary shapes and reinforcing details under severe earthquake excitations. Modules of the simplified method are developed for implementation in the Open System for Earthquake Engineering Simulation framework. Numerical examples of different types of structures are analyzed using the present simplified method under monotonic, cyclic and earthquake loadings. The effects of concrete confinement, steel hardening, stiffness degradation, pinching, and strength deterioration and softening, are simulated in the developed simplified method. Results from the simplified method agree well with finite element and fiber layer models, as well as with experimental testing results. 


\section{ACKNOWLEDGMENTS}

I would like to express my most sincere gratitude to my supervisor Professor D.T.Lau. He has been a precious source of knowledge, guidance, and inspiration during this research. It has been a great honor for me to work with him, and this will remain as an unforgettable experience in my memory.

The assistance provided by Professior K.C. Tsai, M.L. Lin, Y.S. Yuan and C.H. Chen of the National Center for Research on Earthquake Engineering (NCREE) Taiwan for the correlation study of the double-skinned concrete filled tube member and the 3-story 3-bay RCS frame are gratefully acknowledged.

I would like to thank members of faculty, and staff of the Department of Civil and Environmental Engineering at Carleton University for their helpful assistance and kindness, in particular to Professor Khoo for his constructive assistance through this study. I also would be grateful to many of my colleagues in the Civil and Environmental Engineering Department, Viet Phung, Nicolas Londono, Shougui Huang for their encouragement and friendship, and particularly, most sincere thanks to Kate Chang for her great assistance, diligence through the course of this study, and Shadi Ostovari for her initial works on this simplified method.

I would like to thank all my friends, whose constant love and understanding encouraged me to pursue this study. I would like to remember the person who loves me most in whole my life, my grandmother, who passed away during this study in engineering when I was far away from her. 
I wish to take this opportunity to express my love to my parents, for their endless love, support, patience and encouragement in the study and my life. This thesis is dedicated to them. 
To My Parents... and who cares about me 


\section{TABLE OF CONTENTS}

ABSTRACT iii

ACKNOWLEDGMENTS. iv

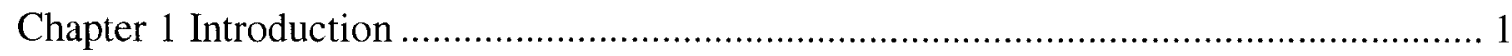

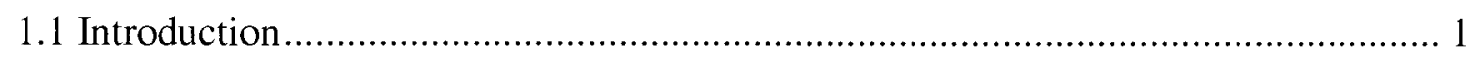

1.2 Literature Review ................................................................................ 3

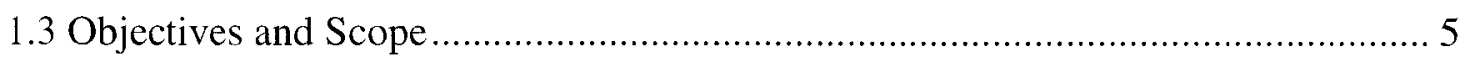

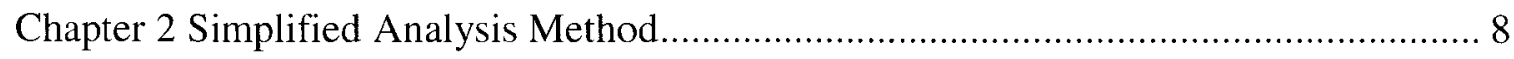

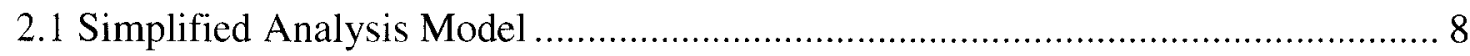

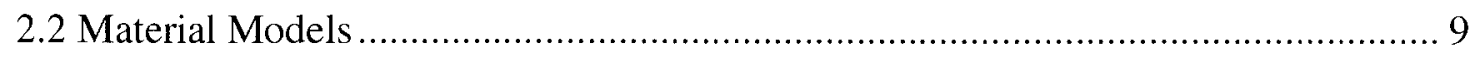

2.2.1 Concrete Model................................................................................ 10

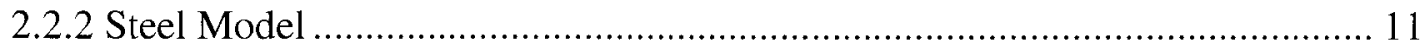

2.3 Direct Formulation................................................................................. 12

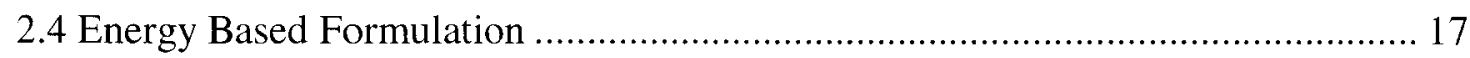

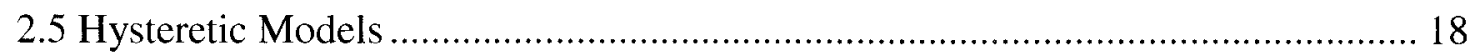

2.5.1 Stiffness Degradation ......................................................................... 19

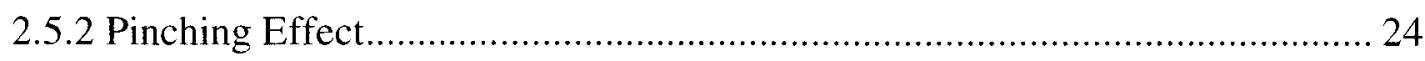

2.5.3 Strength Deterioration and Softening .................................................... 25

Chapter 3 Computer Implementation................................................................ 37

Chapter 4 Numerical Examples ........................................................................ 42

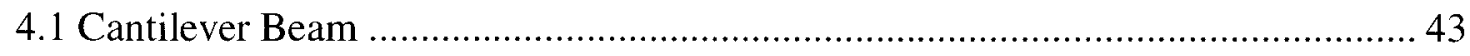

4.2 Double-Skinned Concrete Filled Tube Member.................................................. 44 
4.3 2-Story 2-Bay Reinforced Concrete Frame …................................................ 46

4.4 3-Story 3-Bay Reinforce Concrete-Steel Frame ................................................ 49

Chapter 5 Summary and Conclusions ................................................................ 70

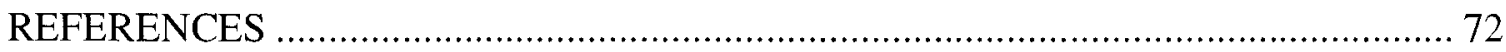




\section{List of Tables}

Table 2-1 Members used in calibration of the unloading stiffness parameter $\beta$ 27

Table 4-1 Material properties of cantilever beam ................................................... 52

Table 4-2 Material properties of DSCFT member................................................. 52

Table 4-3 Dimension and material properties of the 2-story 2-bay RC frame members.. 53

Table 4-4 Dimension and material properties of the 3-story 3-bay RCS frame members 54 


\section{List of Figures}

Figure 2-1 Modified Kent and Park model for unconfined and confined concrete .......... 28

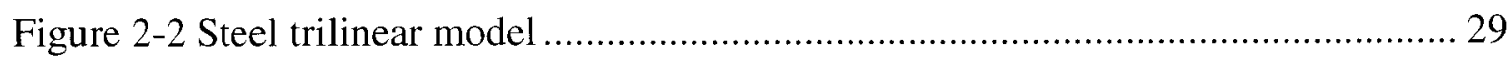

Figure 2-3 Equivalent strain and stress profiles................................................ 30

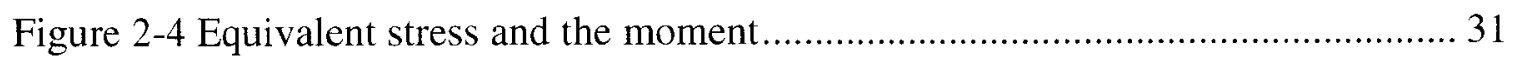

Figure 2-5 Simplified analysis model of reinforced concrete member section ............... 32

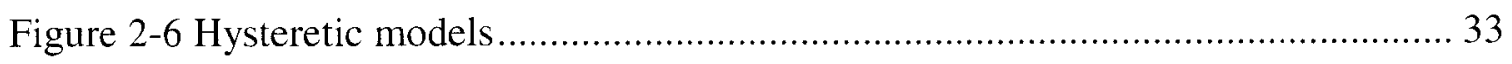

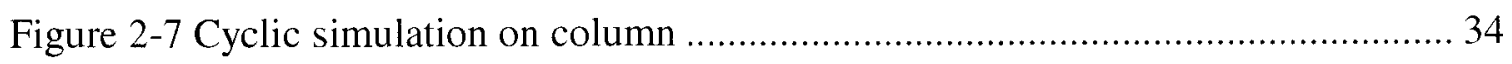

Figure 2-8 Influence of reinforcement ratio, steel yielding strength and concrete

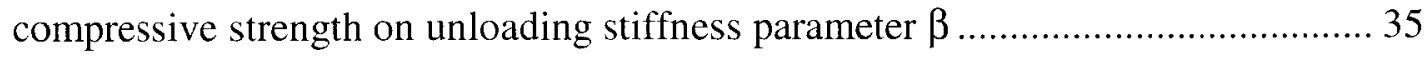

Figure 2-9 Unloading stiffness parameter $\beta$ vs. percentage of axial load $\mathrm{P} / \mathrm{P}_{0} \ldots \ldots \ldots \ldots . . . . .36$

Figure 3-1 Equivalent material model for cyclic loading ..................................... 41

Figure 4-1 Reinforced concrete cantilever beam ................................................. 55

Figure 4-2 Equivalent stress-strain relationship of cantilever beam............................ 56

Figure 4-3 Moment-curvature relationship of cantilever beam .................................. 57

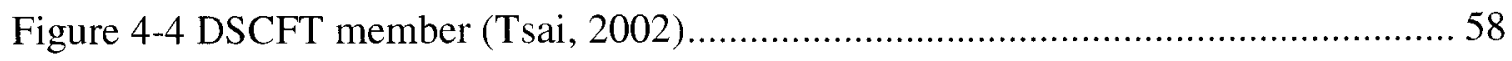

Figure 4-5 Equivalent stress-strain relationship of DSCFT member.......................... 59

Figure 4-6 Moment-curvature relationships of DSCFT member .............................6 60

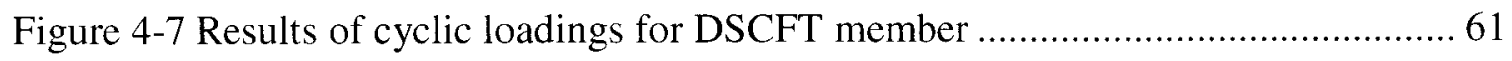

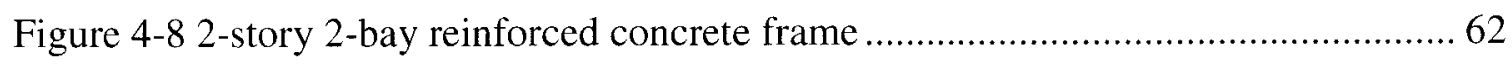

Figure 4-9 Cyclic loading pattern for 2-story 2-bay reinforced concrete frame.............. 63

Figure 4-10 2-Story 2-Bay reinforced concrete frame push over simulation results........ 64

Figure 4-11 2-story 2-bay reinforced concrete frame cyclic loading simulation results .. 65 


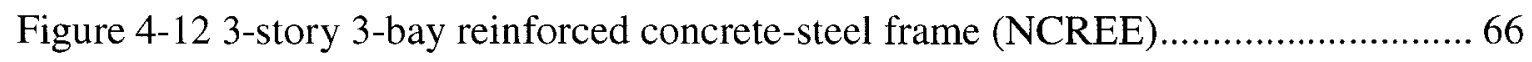

Figure 4-13 The original ground acceleration (before scaling) (PEER) ......................... 67

Figure 4-14 3-story 3-bay frame roof displacement under Chi-chi TCU082 EW CC50/50

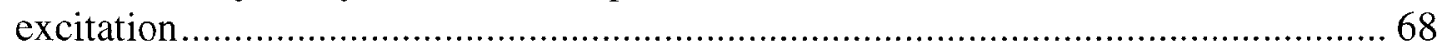

Figure 4-15 3-story 3-bay frame base shear under Chi-chi TCU082 EW CC50/50

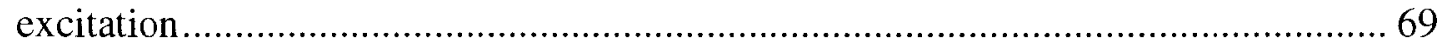




\section{Chapter 1 Introduction}

\subsection{Introduction}

Many existing older structures are inadequate in their earthquake resistance and hence require retrofitting or rehabilitation to conform to the current seismic design requirements. Seismic retrofitting of existing structures is a complex problem. To properly design the retrofit scheme and to minimize the cost, it is important to determine accurately the actual resistant capacity and behavior of structures up to failure. The difficulty of accurately predicting the inelastic and ultimate behavior of reinforced concrete structures arises from the many factors of material nonlinear behavior, such as cracking and crushing of concrete, and yielding and strain hardening of reinforcing steel. The interaction behavior between the concrete and steel materials under high stress state and large deformation, such as anchorage slippage of the reinforcing steel and the confinement of core concrete, are also important phenomena that needed to be considered in accurate modeling of reinforced concrete structures beyond yielding. When analyzing the behavior of reinforced concrete structures subjected to severe cyclic loading, the modeling of the interaction behavior of the concrete and steel materials can greatly affect the nonlinear behavior of the structures (Park et al. 1972; Kunnath et al. 1990; and Spacone and EI-Tawil 2004), as in the hysteretic behavior including stiffness deterioration due to cracking of concrete (Takeda et al. 1971), the pinching behavior due 
to shear and bond deterioration (Popov et al. 1972 and Ma et al. 1976), the strength deterioration and softening due to accumulative severe large deformations and damage on the reinforcing steel and concrete (Park et al 1982; Banon et al. 1982; and Ozecebe and Saatcioglu 1989).

Many extensive analytical and experimental studies have been conducted to investigate the behavior of reinforced concrete structures. Various numerical models have been developed for simulating the nonlinear behavior of reinforced concrete structures, including the fiber layer model and finite element model for analyzing the ultimate behavior of reinforced concrete structures under severe loading conditions. In a fiber model, each structural member section is divided into a number of layers or fibers (Kent and Park 1971) with each layer modeled by a constitutive relationship appropriate for the materials of that particular layer. The moment-curvature relationship of a reinforced concrete member can be determined by using the appropriate concrete and steel consecutive laws for each fiber layer. The member stiffness is then determined by integrating along the member length which may require significant computation effort at each time step in a dynamic time history analysis. In a finite element model, the reinforced concrete member is divided into finite elements with appropriate constitutive models (Cook et al. 1989). Although the finite element model can provide a refined and detailed presentation of the local response behavior of a reinforced concrete structures, its efficiency is questionable due to the complexity involved in developing the models and interpreting the results. Therefore, there is still the need for effective simplified analytical modeling and analysis tools that do not require excessive amount of time and effort in the 
preparation of modeling input data, simple to implement and reasonably accurate in capturing the nonlinear behavior of reinforced concrete structures.

\subsection{Literature Review}

The nonlinear behavior of reinforced concrete members can be effectively analyzed by a number of different numerical hysteretic models developed over the past decades by many researchers. An earlier breakthrough in the analysis of inelastic behavior of reinforced concrete structures is the use of a bilinear hysteretic model proposed by Clough et al. (1965) to represent the section behavior of reinforced concrete members. Since then many other more sophisticated hysteretic models have been developed over the years to model the hysteretic behavior of reinforced concrete structures under cyclic loading. The Takeda model (Takeda et al. 1970) includes the phenomenon of stiffness degradation in reinforced concrete members subject to cyclic loading. Roufaiel and Meyer (1987) introduced a model that accounts for the pinching effects due to shear force and strength degradation after yielding. Park and Ang (1985) developed and proposed a hysteretic model using damage index to qualify the gradual strength degradation and softening behavior in reinforced concrete structural members due to repeated increase of the maximum deformation sustained by the member. However, few of them include all the aspects of the deterioration of strength, stiffness, and ductility characteristics in a comprehensive hysteretic model to capture the inelastic behavior of reinforced concrete members under large reversal cycles loading. The hysteretic models for modeling the phenomena of stiffness degradation, pinching effect, and strength deterioration and 
softening are briefly summarized here. When a reinforced concrete structural member is subjected to repeated cyclic loading beyond its elastic limit, the evolvement of concrete cracking and plastic behavior of the reinforcing steel with associated anchorage slip would lead to the deterioration of the stiffness of the reinforced concrete member at each cyclic loop. A Q-HYST degrading stiffness hysteretic model proposed by Saiidi and Sozen (1979), modified from the Takeda model (Takeda et al. 1974), can efficiently account the unloading stiffness. Laboratory tests conducted on reinforced concrete specimens by Popov et al. (1972) and Ma et al. (1976) have found that there is a strong correlation between the degree of pinching and the magnitude of shear at the section, and that pinching effect reduces the load resistance of the member during reloading. D'Ambrisi and Filippou (1999) have proposed a pinching model by defining a target point during a reloading process reduced from the maximum loading point from previous loading cycles. The strength degradation and softening behavior in reinforced concrete structural members are the results from accumulated incremental damage suffered by the reinforced concrete member due to increase of the maximum deformation in the member response under reversed cyclic loading in the post-elastic range, especially after the structural member has reached its peak strength under high axial loads (Park et al 1982; Ozcebe and Saatcioglu 1989). The strength degradation and softening are controlled by a hysteretic damage index proposed by Park and Ang (1985), which is a function of ductility and absorbed hysteretic energy. 


\subsection{Objectives and Scope}

The aim of the present study is to develop a simple modeling and flexible analysis procedure for the evaluation of nonlinear behavior of reinforced concrete structural members up to the ultimate failure. The approach of the simplified method is to represent the nonlinear behavior of a complex reinforced concrete member by an equivalent model member with a derived material stress-strain relationship, which gives the same momentcurvature response as the original member and can be easily implemented in most structural analysis computer program with nonlinear modeling capabilities. Two formulations of the simplified method by direct equilibrium approach and strain energy approach are presented in this thesis. The equivalent model developed in the present study accounts for the nonlinear material behavior of reinforcing concrete and steel up to the ultimate failure state. The nonlinear behavior of concrete cracking and the softening behavior after peak stress are considered. The effect of confinement on the concrete strength contributing to the overall behavior of the structures is taken into account. The elasto-plastic behavior of reinforcing steel with strain hardening, and the interaction between concrete and reinforcing steel materials are modeled. The equivalent model is implemented in the Open System for Earthquake Engineering Simulation framework (OpenSees) for analysis of the nonlinear behavior of reinforced concrete structures. Under cyclic loading, the equivalent model can accounts for the hysteretic behavior of reinforced concrete structures with consideration of stiffness degradation, pinching effects, strength deterioration and softening. Experimental studies of the behavior of reinforced concrete members have shown that hysteretic behavior of structural members is affected by the axial load level (Roufaiel and Meyer 1987). In this study here, an 
empirical relationship has been developed to account for the influence of axial load in a reinforced concrete member on its unloading stiffness. The proposed simplified method is validated by comparing the simulation results of a reinforced concrete cantilever beam, the experimental results of a double-skinned concrete filled tube member (Tsai et al. 2002), the simulation results of a 2-story 2-bay reinforced concrete frame (Mazzoni et al. 2005), and the experimental results of a 3-story 3-bay reinforced concrete-steel (RCS) frame tested at the National Center for Research on Earthquake Engineering (NCREE) Taiwan (Chen et al. 2003 and Cordova et al. 2003). The reinforced concrete frames are subjected to monotonic, cyclic and earthquake loadings. The proposed simplified model results are compared with the experimental data, the numerical results by the fiber layer model, and the numerical results by the finite element model.

This thesis has two main objectives: (a) to describe the formulations of the simplified method and the derivation of the equivalent model, (b) to verify the accuracy and effectiveness of the equivalent model derived by the simplified method in analyzing the nonlinear behavior of reinforced concrete structures under dynamic loadings.

This thesis is organized into six chapters as follows:

Chapter 1 presents the introduction of the problems, literature review and the objectives and the scope of the thesis.

Chapter 2 gives a description of the simplified analysis method.

Chapter 3 describes the implementation of the equivalent model in the computer software framework 
Chapter 4 presents the numerical example structures and analysis results.

Chapter 5 summarizes the results and makes conclusions for this study. 


\section{Chapter 2 Simplified Analysis Method}

\subsection{Simplified Analysis Model}

The basic approach of the simplified analysis model is similar to the fiber layer model, except that only distinct states in the behavior of the modeling reinforced concrete member are considered in the formulation. For flexure behavior, the following assumptions are considered in the formulation of the simplified analysis procedure:

1. Plane sections of the member remain plane when a member is subjected to deformation. Consequently, the longitudinal strain in the steel and concrete materials at a plane section is directly proportional to the distance from the neutral axis.

2. The stress-strain relationship for the steel is modeled by a trilinear model.

3. The tensile strength of concrete is assumed to be negligible.

4. The stress-strain relationships of confined and unconfined concrete under compression are modeled by a modified Kent and Park concrete model.

In the simplified method, the original structural member section is modeled by an equivalent member section of homogeneous nonlinear material with a specified stressstrain relationship, which is derived based on the requirement that the equivalent section 
has the same moment-curvature behavior as the original section. The equivalent member section is defined as a rectangular section, which has the same height and cross-sectional area of the original reinforced concrete section.

There are two approaches in the formulation of the simplified method, namely, direct formulation and energy based formulation. In the direct formulation, selected states in the behavior of the reinforced concrete members are analyzed to establish directly points on the specified stress-strain relationship of the nonlinear homogeneous material model of the equivalent member by strain compatibility and equilibrium of internal resultant forces. For the energy based formulation, similar procedures are applied on selected states in the behavior of the reinforced concrete member, but instead consider strain energy and strain compatibility in the derivation of the specified stress-strain relationship of the nonlinear equivalent member material. Preliminary study (Deng et al. 2003) indicates that the derived stress-strain relationship of the equivalent model determined from the direct formulation in some cases can become unstable after the elastic limit is exceeded due to difficulty in convergence. The energy approach based on the consideration of equivalent strain energy can eliminate this problem and give better prediction in the behavior of the equivalent simplified model.

\subsection{Material Models}

The material models adopted for representation of the behavior of concrete and steel are briefly described here. The constitutive model for concrete developed by Kent and Park 
(1971) for confined and unconfined concrete is implemented in the simplified analysis procedure. The behavior of reinforcing steel materials is approximated by a trilinear stress-strain relationship considering the effect of strain hardening.

\subsubsection{Concrete Model}

Many studies have been conducted on the stress-strain relationship of concrete confined by transverse reinforcement under compression. Observations and laboratory tests have shown that if the compression zone of a concrete beam or column is confined by closelyspaced stirrup ties, hoops or spirals, the ductility of concrete is significantly enhanced and the member can sustain deformations of large curvature (Kent and Park 1971; Park et al. 1982; and Ozcebe and Saatcioglu 1987). In the simplified method, the modified Kent and Park concrete model (Park et al. 1982) is adopted for modeling the material behavior of concrete under compression. The formulations of the stress-strain relations of confined and unconfined concrete of the model are summarized here.

The constitutive model consists of an ascending branch represented by a second-degree parabolic curve and a descending linear part, as shown in Figure 2-1.

The ascending parabola is expressed by Equation (2.1)

$$
f_{c}=k f_{c}^{\prime}\left[\frac{2 \varepsilon_{c}}{\varepsilon_{0} k}-\left(\frac{\varepsilon_{c}}{\varepsilon_{0} k}\right)^{2}\right] \quad \varepsilon_{c} \leq k \varepsilon_{0}
$$


where $\varepsilon_{c}$ is the longitudinal concrete strain, $f_{c}^{\prime}$ is the compressive strength of concrete, $\varepsilon_{0}$ is the strain of unconfined concrete corresponding to $f_{c}^{\prime}$, and $k$ is a confinement coefficient. For unconfined concrete, the parameter $k$ is equal to one. A commonly accepted assumption for unconfined concrete is $\varepsilon_{o}=0.002$ and $\varepsilon_{u}=0.0035$ (CSA 1998).

For strain greater than the corresponding strain at peak stress, the softening branch of the stress-strain relationship is approximated by a straight line presented in Equation (2.2)

$$
f_{c}=k f_{c}^{\prime}\left[1-Z_{m}\left(\varepsilon_{c}-\varepsilon_{0} k\right)\right] \geq 0.2 k f_{c}^{\prime} \quad \varepsilon_{c}>k \varepsilon_{0}
$$

where $Z_{m}$ is the stress declining ratio for the confined concrete after peak stress.

For concrete under confinement, a perfectly plastic residual behavior is assumed at high strain level to account for the load carrying capacity of crushed concrete still effectively confined by the transverse steel. The confinement effect on the strength of concrete represented by the confinement coefficient $k$ increases the concrete peak stress from $f_{c}^{\prime}$ to $k f_{c}^{\prime}$. It is assumed that confined concrete can sustain a constant stress of $0.2 k f_{c}^{\prime}$ at strains greater than $\varepsilon_{20 c}$.

\subsubsection{Steel Model}

For simplification purpose, a trilinear stress-strain relationship shown in Figure $2-2$ is adopted to model the behaviour of reinforcing steel under tension or compression. The 
possibility of buckling of the compression steel ignored. Other steel models can adopted for better representation of the behavior of steel.

\subsection{Direct Formulation}

Figures 2-3 to 2-5 illustrate the basic steps in the derivation of the specified stress-strain relationship of the nonlinear equivalent member material by strain compatibility and direct equilibrium of internal resultant forces. To illustrate the procedure for the derivation of the stress-strain relationship of the equivalent member section, a rectangular reinforced concrete beam member is analyzed as an example here. The procedure can be extended to the analysis of any reinforced concrete or concrete-steel composite structural members of arbitrary shapes with different reinforcing details based on the same approach.

Assuming the strain at the top surface of the rectangular member section at a particular state is $\varepsilon_{t o p}$, and the neutral axis is located at a depth of c measured from the top of the member section as shown in Figure 2-3, the curvature $\phi$ of the section can be expressed by Equation (2.3)

$$
\phi=\frac{\varepsilon_{t o p}}{h-c}
$$

where $h$ is the section height of the member.

Using the concrete constitutive model by the modified Kent and Park and the steel material model as shown in Figures 2-4(b) and 2-4(c), the neutral axis is determined by 
an iterative process based on equilibrium of the internal resultant forces of the member section. The internal force $F$ and moment $M$ of the section, can be obtained by integrating the stress distributions on concrete and steel over the member section area $A$ as follows

$$
\begin{aligned}
F & =\int \sigma d A \\
M & =\int \sigma y d A
\end{aligned}
$$

where $y$ is the moment arm of the stress in the member section.

As discussed earlier, an equivalent member section shown in Figure 2-5(e) is assumed to be composed of a uniform homogeneous material. The characteristic of this material is that the stress-strain relationship of the equivalent section, as shown in Figure 2-5(f), should lead to the same moment-curvature behavior as the original member section, as shown in Figures 2-5(d) and 2-5(g). In the formulation adopted here, the equivalent section is defined to be rectangular section, which has the same height and same crosssectional area of the original member section. In the derivation, the equivalent section is derived by having the same curvature as the original member section. The homogeneous material is assumed to have the same stress-strain behavior in both tension and compression in the derivation of the equivalent section as shown in Figure 2-3.

Typical states of the reinforced concrete member section considered in the formulation are cracking of concrete, yielding of reinforcing steel, peak stress in concret, reinforcing steel hardening, residual stress in confined concrete, and ultimate fracture of reforcing 
steel, as illustrated in Figure 2-5. To obtain a more accurate and complete equivalent stress-strain relationship for the analyzed reinforced structural member, additional states in the behavior of the reinforced structural member can be analyzed. A linear interpolation is assumed between two consecutive states in the stress-strain relationship of the equivalent material.

From the linear strain variation of the equivalent member section with the same curvature as the original member, the maximum equivalent strain at the extreme fiber of the equivalent member section is given by Equation (2.6)

$$
\mathcal{E}_{e \psi}=\phi_{e \psi}\left(\frac{h_{e \psi t}}{2}\right)
$$

where $\phi_{e q}=\phi$ and $h_{e q}$ is equal to the height of the reinforced concrete member section.

Considering the first critical state of initial cracking of concrete, the equivalent cracking stress of the equivalent member section required to give the same moment-curvature behavior as the original analyzed reinforced concrete section is determined as follows

$$
\sigma_{(e q) c r}=\frac{M_{c r} c_{e q}}{I_{e q}}
$$

where $M_{c r}$ is the cracking moment of the reinforced concrete structural member section, the equivalent neutral axis depth $c_{e \varphi}=\frac{h_{e q}}{2}$, and $I_{e \varphi}$ is the moment of inertial of the equivalent member section. 
In the second state, as illustrated in Figure 2-4(a), the equivalent stress can be determined by

$$
\begin{gathered}
\frac{M_{2}}{2}=\delta M_{1}^{a}+\delta M_{1}^{b}+\frac{1}{2} \Delta \sigma_{(e q) 2}\left(h_{1}\right)\left(b_{e q}\right)\left(\frac{h_{e q}}{2}-\frac{h_{1}}{3}\right) \\
\sigma_{(e q) 2}=\sigma_{(e q) 1}+\Delta \sigma_{(e q) 2}
\end{gathered}
$$

where $M_{2}$ is moment in the second state of the member, $M_{1}^{a}$ and $M_{1}^{b}$ are the moment expressed in a hydrostatic manner of the rectangular equivalent stress block and the triangular equivalent stress block, respectively; as illustrated in Figure 2-4(a). $\delta M_{1}^{\prime \prime}$ and $\delta M_{1}^{b}$ are determined by the Equations 2-10 and 2-11, respectively,

$$
\begin{gathered}
\delta M_{1}^{a}=\Delta \sigma_{(e q) 1}\left(h_{1}\right)\left(b_{e q)}\right)\left(\frac{h_{e q}}{2}-\frac{h_{1}}{2}\right) \\
\delta M_{1}^{b}=\frac{1}{2} \Delta \sigma_{(e q) 1}\left(h_{1}\right)\left(b_{e q}\right) \frac{2}{3}\left(\frac{h_{e q}}{2}-h_{1}\right)
\end{gathered}
$$

where $h_{1}$ is the height from the top fiber of the equivalent model to the fiber of equivalent strain of the first state state. $\Delta \sigma_{(e q) 1}$ is equal to the equivalent stress $\sigma_{(e q) 1}$, $b_{e q}$ is the width of equivalent section. 
The derivation procedure can be extended to analyze the yielding and other nonlinear states of the original reinforced concrete member. For each state, the moment can be expressed as follows

$$
\frac{M_{i}}{2}=\sum_{1}^{i-1} \delta M_{n}^{a}+\sum_{1}^{i-1} \delta M_{n}^{b}+\frac{1}{2} \Delta \sigma_{(e q) i}\left(h_{i-1}\right)\left(b_{e q}\right)\left(\frac{h_{e q}}{2}-\frac{h_{i-1}}{3}\right)
$$

where $M_{i}$ is the moment at the $\mathrm{i}^{\text {th }}$ state, and

$$
\begin{aligned}
& \sum_{1}^{i-1} \delta M_{n}^{a}=\sum_{1}^{i-1} \Delta \sigma_{(e q) n}\left(h_{n}\right)\left(b_{e q}\right)\left(\frac{h_{e q}}{2}-\frac{h_{n}}{2}\right) \\
& \sum_{1}^{i-1} \delta M_{n}^{b}=\sum_{1}^{i-1} \frac{1}{2} \Delta \sigma_{(e q) n}\left(h_{n}\right)\left(b_{e q}\right) \frac{2}{3}\left(\frac{h_{e q}}{2}-h_{n}\right)
\end{aligned}
$$

where $\Delta \sigma_{(e q) n}$ is the change of stress from two consecutive states, $\sum_{1}^{i-1} \delta M_{n}^{u}$ is the summation of moment of the rectangular equivalent stress block from the first state to the $(\mathrm{i}-1)^{\mathrm{th}}$ state, $\sum_{1}^{i-1} \delta M_{n}^{b}$ is the summation of the moment of the triangular equivalent stress block (i-1) $)^{\text {th }}$ state.

After obtaining the equivalent strain of the $i^{\text {th }}$ state from the moment-curvature relationship of the original member section, the stress increment $\Delta \sigma_{(e q) i}$ in Equation (2.12) can be solved to give the equivalent stress at the $\mathrm{i}^{\text {th }}$ state as follows

$$
\sigma_{(e q) i}=\sigma_{(e q) i-1}+\Delta \sigma_{(e q) i}
$$


By repeating the derivation procedures as given in Equations (2.3) to (2.15) for each selected states of the original member behavior, the complete stress-strain relationship of the equivalent member material can be obtained.

\subsection{Energy Based Formulation}

Numerical results from preliminary studies (Deng et al. 2003) using the direct formulations presented in previous section have shown that the derived stress-strain relationship after the elastic limit may become unstable in the inelastic range when applied to the modeling of some reinforced concrete member sections. An alternative approach to derive the equivalent stress-strain relationship by the energy method is formulated. In the energy based formulation, similar procedures are applied to selected states in the behavior of the reinforced concrete member by consideration of strain energy instead of direct equilibrium in the derivation of the nonlinear equivalent member material. For structural member under flexure, the strain energy is determined by

$$
U=\int_{L} \frac{M^{2}}{E I} d x=\int \sigma \varepsilon d V
$$

where $E$ is the elastic modulus and $I$ is the moment of inertia of the member. Linear relationship is assumed for the stress-strain behavior between two consecutive modeling states. The strain energy of an equivalent member of solid cross-sectional area can be expressed by strain energy density in terms of equivalent stress and strain as follows

$$
\Delta u_{(e q) j}=\frac{\sigma_{(e q) j}+\sigma_{(e q) j-1}}{2}\left\{\varepsilon_{(e q) j}-\varepsilon_{(e q) j-1}\right\}
$$


where $\Delta u_{(e q) j}$ is the change of strain energy density from the $(\mathrm{j}-1)^{\text {th }}$ to the $\mathrm{j}^{\text {th }}$ state, $\sigma_{(e q) j}$ is the equivalent stress at the $\mathrm{j}^{\text {th }}$ state, $\varepsilon_{(e q) j}$ is the strain at the $\mathrm{j}^{\text {th }}$ state, $\sigma_{(e q) j-1}$ and $\mathcal{E}_{(e q) j-1}$ are the stress and strain at the $(\mathrm{j}-1)^{\text {th }}$ state, respectively. After the strain energy density $\Delta u_{(e q) j}$ is obtained from two consecutive states of the reinforced concrete member, the equivalent stress $\sigma_{(e q) j}$ in Equation (2.17) can be solved.

The axial load carried by a structural member not only alters the stress distribution in the member cross-section, but also has an influence on the degrading behavior in its stiffness and strength under cyclic loading. Roufaiel and Meyer (1987) have shown that the axial force increases the yield moment of a member section. Numerical analyses conducted in this study also show that the axial load has significant influence on the initial stiffness of the equivalent member under cyclic loading. In the formulation here, the axial load effect of the member is taken into account as follows

$$
\sigma_{(e q) j}+\frac{P}{A_{e q}}
$$

where $\sigma_{(e q) j}$ is the equivalent stress computed by Equation $(2.11), P$ is the axial load, $A_{e q}$ is the cross-sectional area of the equivalent member.

\subsection{Hysteretic Models}

Many hysteretic models have been developed over the years to model the hysteretic behavior of reinforced concrete structures under cyclic loading. However, few of them 
include all the aspects of the deterioration of strength, stiffness, and ductility characteristics of reinforced concrete members under large loading reversal cycles. The hysteretic models adopted for implementation in the equivalent model derived from the simplified method here incorporates all these important phenomena which significantly influence the nonlinear behavior of reinforced concrete structures. The phenomena of stiffness degradation, pinching effect, and strength deterioration and softening are modeled. The hysteretic models are illustrated in Figure 2-6 and briefly summarized herein.

\subsubsection{Stiffness Degradation}

When a reinforced concrete structural member is subjected to repeated cyclic loading beyond elastic limit, the evolvement of concrete cracking and plastic behavior of the reinforcing steel with associated anchorage slip would lead to the deterioration of the stiffness of the reinforced concrete member at each cyclic loop. The stiffness degradation model implemented in the equivalent model of this study is a Q-HYST degrading stiffness hysteretic model by Saiidi and Sozen (1979) modified from the Takeda model (Takeda et al. 1974), as shown in Figure 2-6(a). For the hysteretic model, the unloading stiffness $K_{u}$ from the maximum response at the end of each cycle is reduced by a factor from the original initial stiffness $K_{0}$, after completion of the unloading and starting of the reloading, the standard hysteretic model has the stiffness further reduced by targeting towards the yield state in the opposite direction. However, the stiffness at this reloading stage may exhibit pinching characteristics. This pinching behavior is discussed later in 
the pinching model. Beyond the yield state, the hysteresis behavior in the negative direction follows the same form in the positive direction.

The unloading stiffness of a reinforced concrete member is influenced by the level of axial load carried by the member. In the formulation of the equivalent member, the unloading stiffness $K_{u}$ is related to the ductility level and the initial stiffness as follows,

$$
K_{u}=K_{o} \cdot\left(\frac{\delta_{m}}{\delta_{y}}\right)^{-\beta}
$$

where $K_{u}$ is the unloading stiffness of the equivalent member, $K_{v}$ is the initial stiffness, $\delta_{m}$ is the maximum deformation attained in the direction of the loading during the previous loading cycles, $\delta_{y}$ is the yielding deformation of the equivalent member, $\beta$ is a parameter that determines the degraded unloading stiffness and is related to the axial load level.

In the study by Roufaiel and Meyer (1987), it is shown that the axial force increases the yield moment of a section but reduces the ultimate failure curvature considerably. The axial load effect on the dynamic behavior of structures can be very complex. For a structure under 3-D earthquake loading, the axial forces in the columns vary during the responses as a result of the overturning moment and vertical accelerations of the ground motions coupled with the P-delta effect if large lateral displacement is experienced by the structure. Furthermore, for a damaged reinforced concrete column member, analysis results obtained by Kwan et al (2001) have shown that the elastic unloading behavior of 
steel dominates the unloading behavior of deteriorated member under cyclic loading. This indicates that the unloading stiffness of reinforced concrete member is also related to the amount of steel reinforcement and the strength of the reinforcing steel of the member.

In this study, analyses of the example structures indicate that the axial load has significant influence on the unloading stiffness of the equivalent member subject to cyclic loading. Computer simulations of the reinforced concrete member behavior under cyclic loading by fiber model in OpenSees have been carried out to evaluate the influence of axial load on unloading stiffness for the equivalent member formulation. A regression analysis has been carried out to obtain the empirical relation of the axial load effect on the unloading stiffness as a function of the reinforcement ratio, the yield strength of steel, and concrete compressive strength. The height of the analyzed structural members is $4000 \mathrm{~mm}$ and the dimension and material properties of the analyzed structural members in the parametric study and regression analysis are given in Table 2-1.

The example structural members are analyzed under cyclic lateral loading under different level of constant axial load. A lateral displacement control pattern is applied in the cyclic loading simulation on the structural members, as shown in Figure 2-7. The unloading stiffness parameter $\beta$ of the equivalent member is determined by best matching the simulation results by the steel-concrete fiber model. In the simulation using the steel concrete fiber model, the material models are employed steel02 for steel considering isotropic strain hardening and the transition control from elastic to plastic (Fillipou et al. 1983 and Mazzoni et al. 2005), and concrete01 for concrete with degraded linear 
unloading and reloading stiffness, and no tensile strength in OpenSees (Mazzoni et al. 2005), considering both the modeling cases of confined and unconfined concrete. The steel and concrete material models in Opensees are the common material models that enable to capture the overall behavior of reinforced concrete structures under cyclic loading (Cordova et al. 2003).

Figure 2-8(a) shows the influence of the reinforcement ratio of the reinforced concrete members on the unloading stiffness parameter $\beta$ of the equivalent members under constant axial load. The cross sectional area of reinforced concrete members is $625 \mathrm{~mm} \mathrm{x}$ $625 \mathrm{~mm}$. The concrete compressive strength is $44.5 \mathrm{MPa}$, and the yield strength of reinforcing steel is $527 \mathrm{MPa}$. The cases of reinforcement ratio of $0.0095,0.0190$ and 0.0286 are analyzed. The analysis results clearly show as the reinforcement ratio of the reinforced concrete member increases, the unloading stiffness parameter $\beta$ of the equivalent member decreases under the same axial load. Numerical analyses have also been carried out to assess the influence of concrete compressive strength and yielding strength of reinforcing steel on the unloading stiffness. Results show that the unloading stiffness parameter $\beta$ of the equivalent member decreases as the product of reinforcement ratio, the yield strength of reinforcing steel and concrete compression strength of the original reinforced concrete member increases, as shown in Figure 2-8(b).

Based on the stimulation data, regression analyses have been carried out to establish the relation between the unloading stiffness parameter $\beta$ of the equivalent member as representing the axial load effect, the reinforcement ratio, the yield strength of steel, and 
the concrete compressive strength of the original reinforced concrete member. The proposed equation of the unloading stiffness parameter $\beta$ of the equivalent member is expressed as follows

$$
\beta=\frac{b_{o}+b_{1} \frac{P}{P_{o}}+b_{2} \sqrt{\frac{\rho f_{y}}{f_{c}}}}{1+b_{3} \frac{P}{P_{o}}+b_{4} \sqrt{\frac{\rho f_{y}}{f_{c}}}}
$$

where $P$ is the axial load, $P_{o}$ is the maximum axial load resistance, $\rho$ is the reinforcement ratio, $f_{c}$ is the compressive strength of concrete, $f_{v}$ is the yield strength of the reinforcing steel, and $b_{0}, b_{1}, b_{2}, b_{3}, b_{4}$ are the constants, which are calibrated by the steel concrete fiber model to be $0.030,14.02,0.151,15.54$ and 7.075 . The influence of the axial load on the unloading stiffness parameter $\beta$ of the equivalent member is shown in Figure 2-8. Each curve in Figure 2-8 represents the variation of the unloading stiffness parameter $\beta$ with the axial load level of the member. Each of the analyzed reinforced concrete members has a different reinforcement ratio, different concrete compression strength, or different type of reinforcing steel. The axial load applied to each member is varied up to about 40 percent of the maximum axial load resistance of the member. It is observed that for each member, as the axial load increases, the unloading stiffness parameter $\beta$ of the equivalent member increases. As showed in Figure $2-8$, the simulation results by the proposed empirical expression $\beta$ as given in Equation (2.14) agree well with the calibrated $\beta$ by the steel concrete fiber model. 


\subsubsection{Pinching Effect}

The pinching behavior is a significant characteristic of structural member upon reloading under reversed cyclic loading. It is associated with shear deformation behavior and slippage of the reinforcing steel against the adjacent damaged concrete as the bond deteriorates. Laboratory tests conducted on reinforced concrete specimens by Popov et al. (1972) and Ma et al. (1976) have found that there is a strong correlation between the degree of pinching and the magnitude of shear at the section, and that pinching effect reduces the load resistance of the member during reloading. D'Ambrisi and Filippou (1999) have proposed a pinching model by defining a target point during a reloading process reduced from the maximum or minimum loading point from previous loading cycles, as illustrated in Figure 2-6(b). The pinching effect leads to the constriction of the hysteresis loop, which reduces the amount of dissipated energy during the cyclic response of the member. The pinching reference point $\left(\delta_{p}, F_{p}\right)$ is determined by the pinching parameters $c_{1}$ and $c_{2}$ as follows

$$
\begin{gathered}
\delta_{p}=\left(c_{1}-0.5\right) \delta_{o, \max } \\
F_{p}=c_{2} F_{m}
\end{gathered}
$$

where $\delta_{0, \max }$ is the sum of the absolute values of two unloading deformations from previous load cycle, $F_{m}$ is the maximum strength attained in previous load cycle at the same direction, respectively; $c_{1}$ and $c_{2}$ are the parameters used to control the pinching level. 


\subsubsection{Strength Deterioration and Softening}

The strength degradation and softening behavior in reinforced concrete structural members are the results from accumulated incremental damage suffered by the reinforced concrete member due to increase of the maximum deformation in the member response under reversed cyclic loading, in the post-elastic range, especially after the structural member has reached its peak strength under high axial loads (Park et al 1982; Ozcebe and Saatcioglu 1989). Experimental study by Banon et al. (1982) has shown that the spalling of concrete, the presence of shear, and slippage deformations contribute to the strength deterioration of the member. Typical strength deterioration and softening behavior are illustrated in Figure 2-6(c). The strength degradation and softening are controlled by a hysteretic damage index, proposed by Park and Ang (1985), which is a function of ductility and absorbed hysteretic energy

$$
\begin{aligned}
& \delta_{D}=\delta_{m}(1+D) \\
& F_{D}=F_{m}(1-D)
\end{aligned}
$$

where $\delta_{D}$ and $F_{D}$ are the current maximum deformation and strength due to strength deterioration and softening, respectively. $D$ is the current value of the hysteretic damage index for deformation and strength, which are formulated as follows

$$
D=\frac{\delta_{m}}{\delta_{u}}+\frac{\alpha}{Q_{y} \delta_{u}} \int d E
$$

where $\delta_{m}$ is the maximum deformation attained in the direction of the loading during the previous loading cycles, $\delta_{u}$ is the ultimate deformation capacity under static loading, 
$\alpha$ is the coefficient for cyclic loading effect, $Q_{y}$ is the calculated yield strength, and $d E$ is the incremental absorbed hysteretic energy. 
Table 2-1 Members used in calibration of the unloading stiffness parameter $\beta$

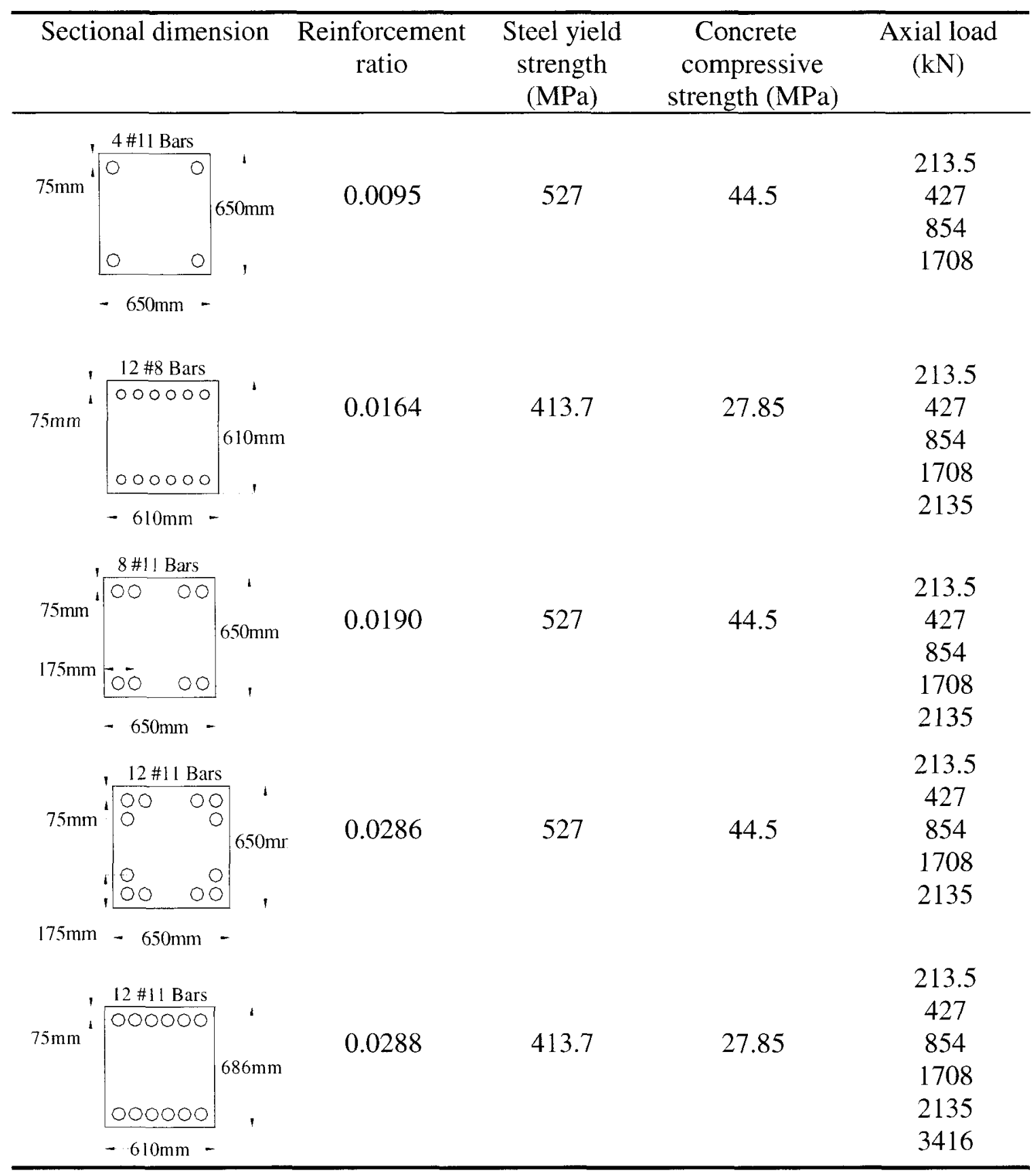




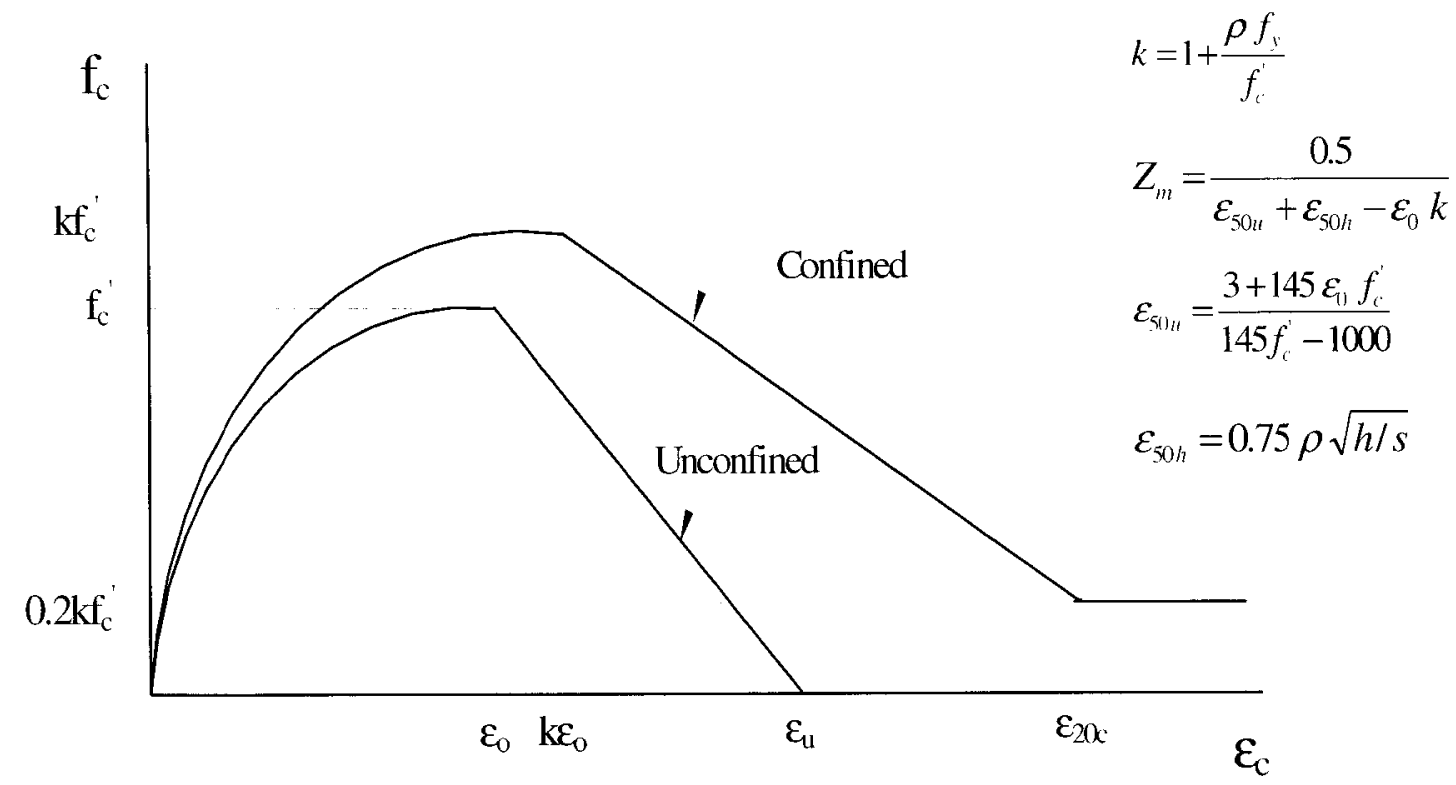

Figure 2-1 Modified Kent and Park model for unconfined and confined concrete 


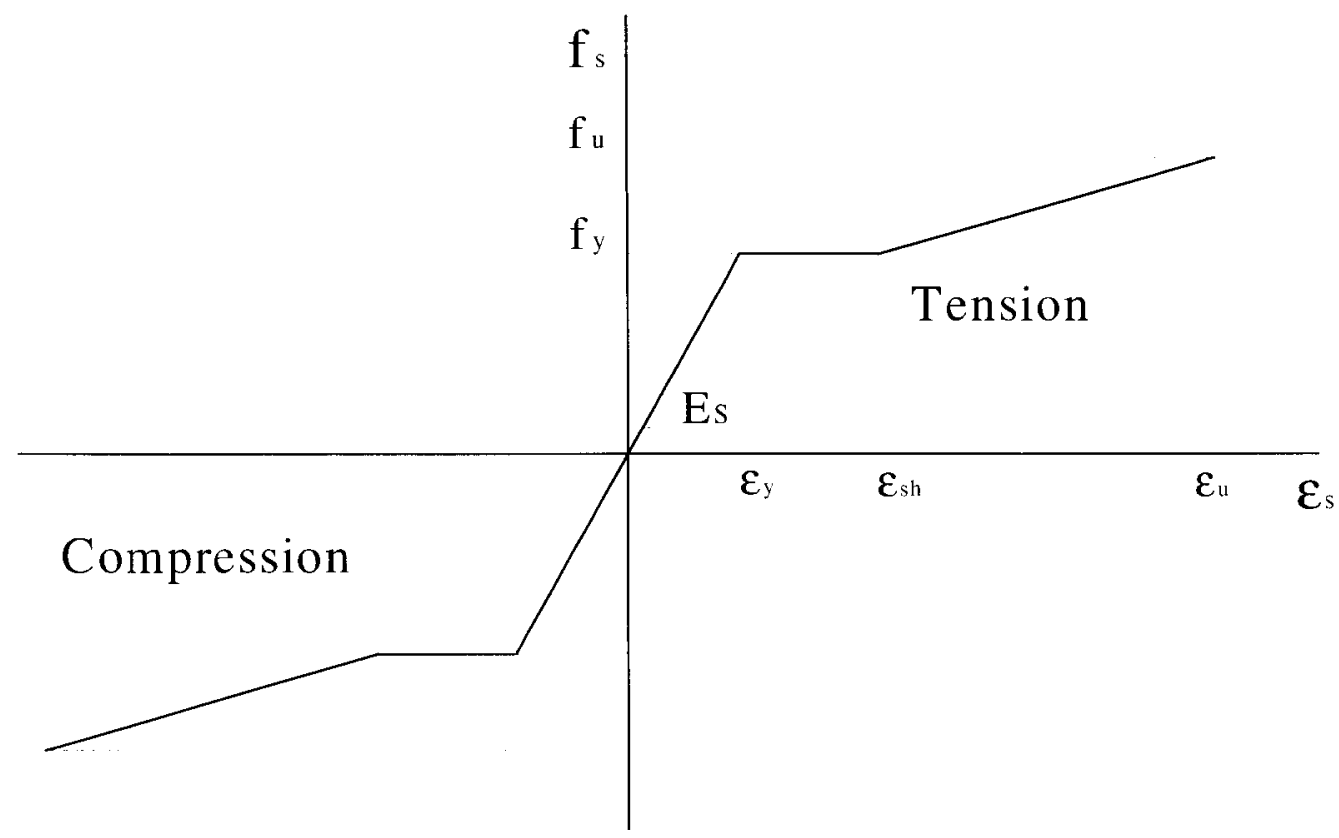

Figure 2-2 Steel trilinear model 
요

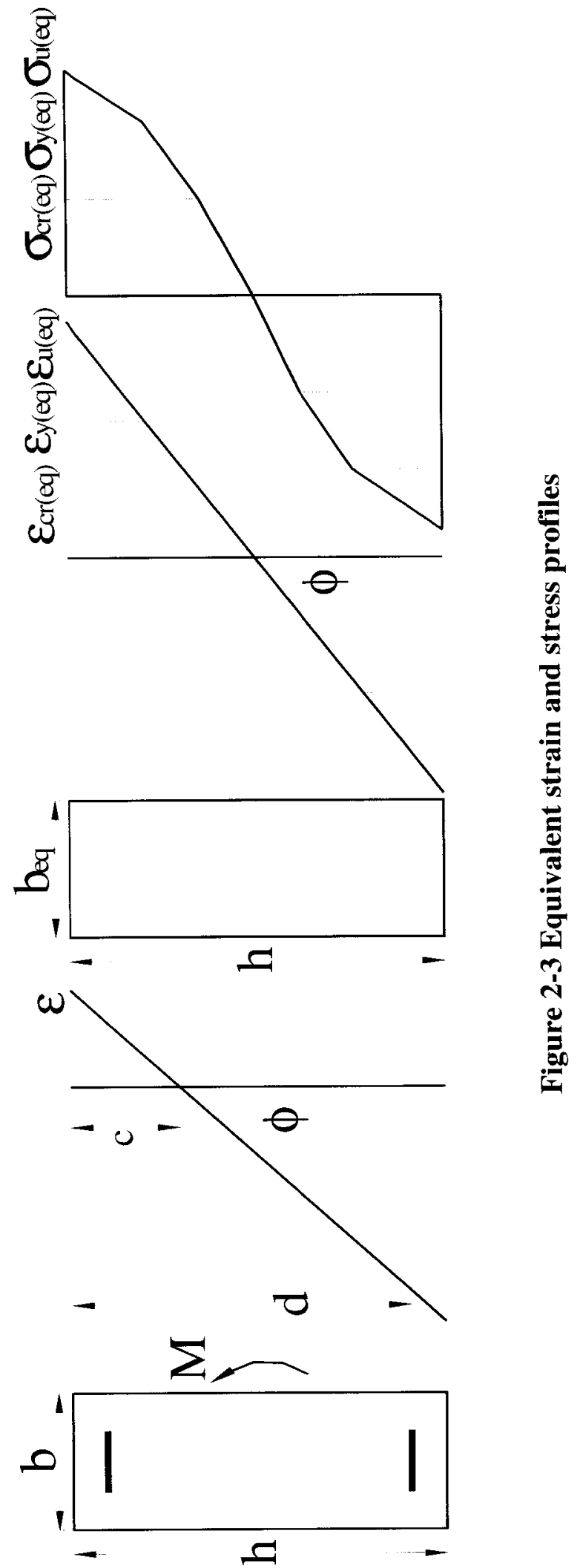




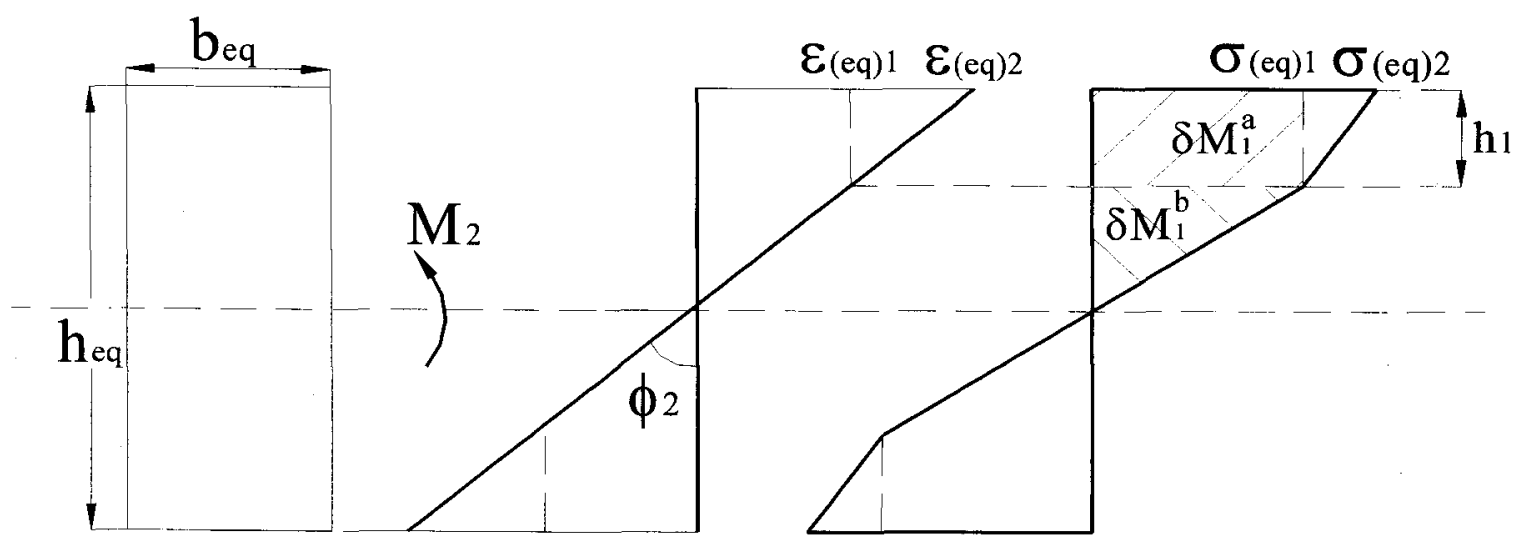

(a) 2 states

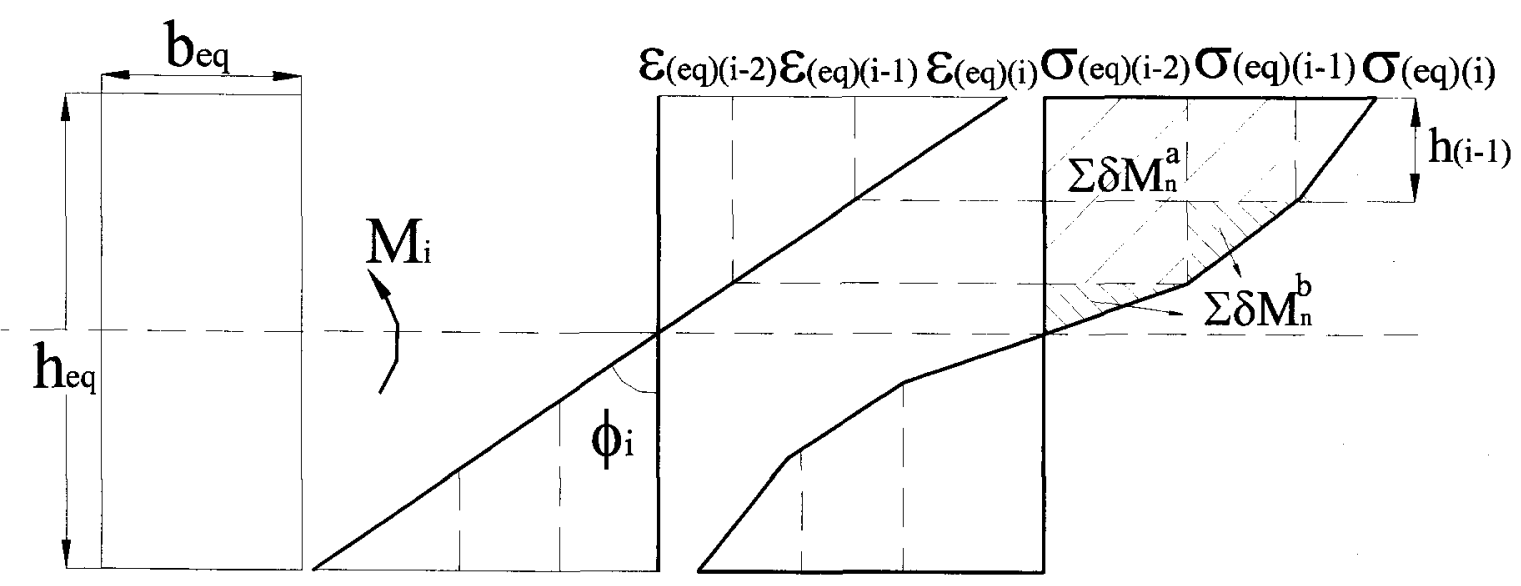

(b) i states

Figure 2-4 Equivalent stress and the moment 


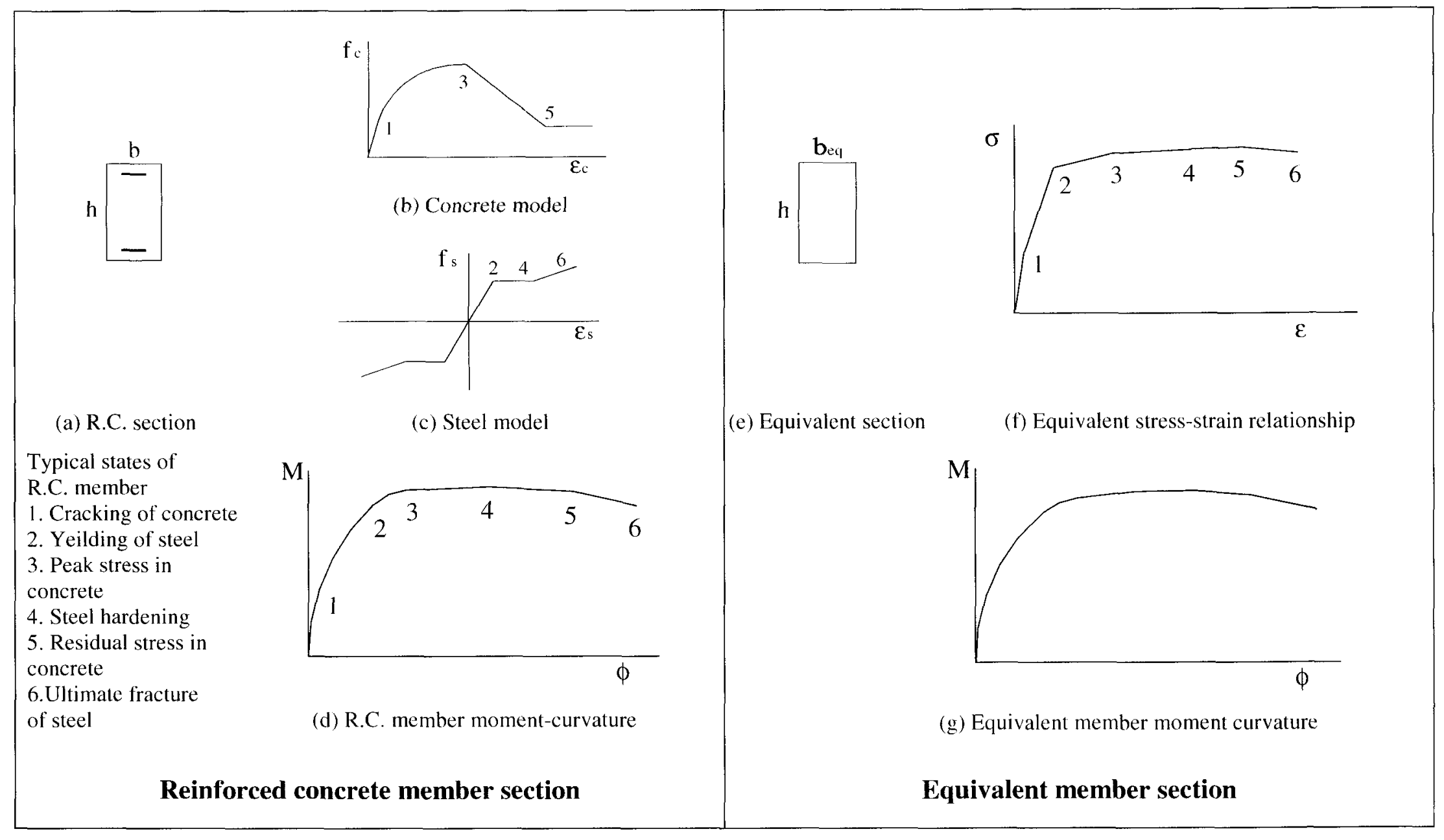

Figure 2-5 Simplified analysis model of reinforced concrete member section 


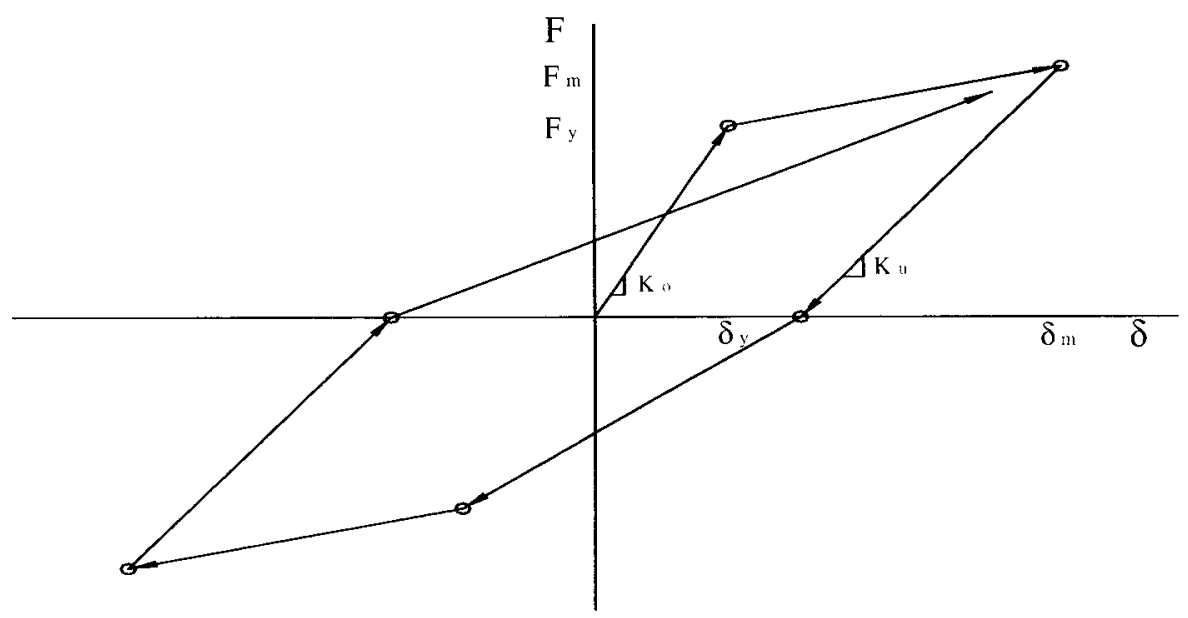

(a) Stiffness degradation

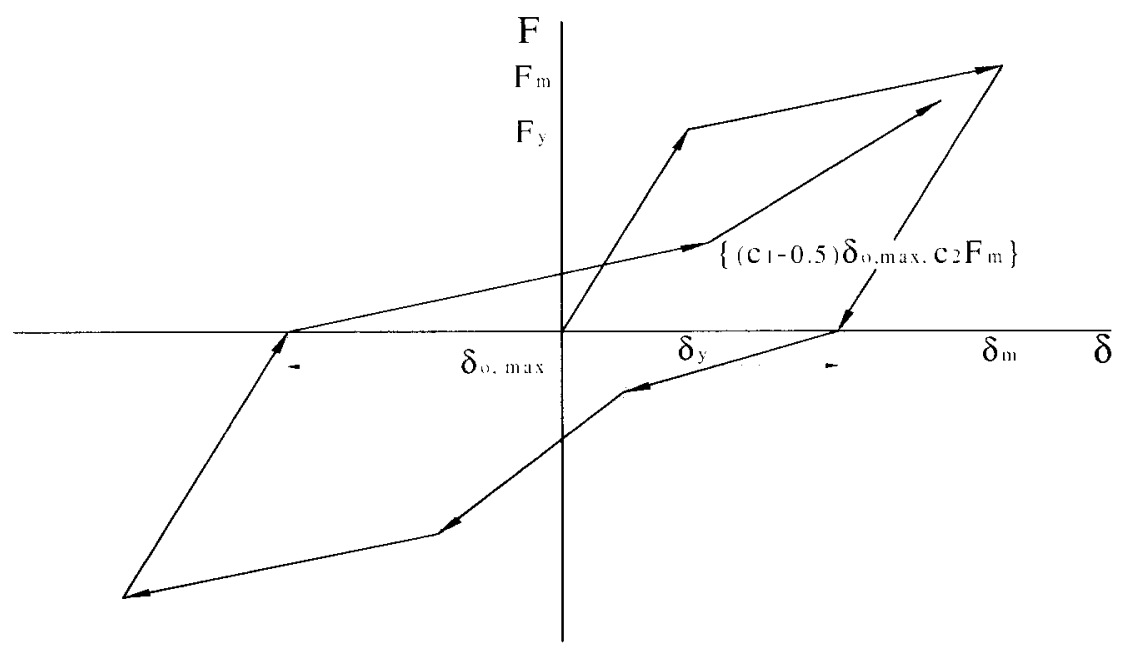

(b) Pinching effect

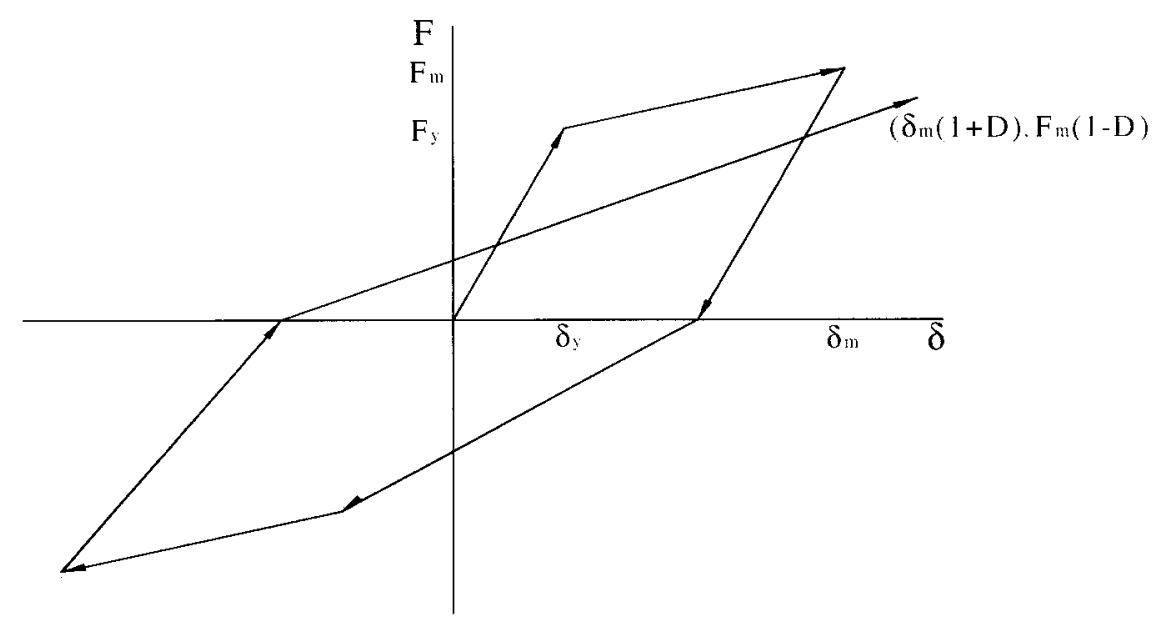

(c) Strength deterioration and softening

Figure 2-6 Hysteretic models 


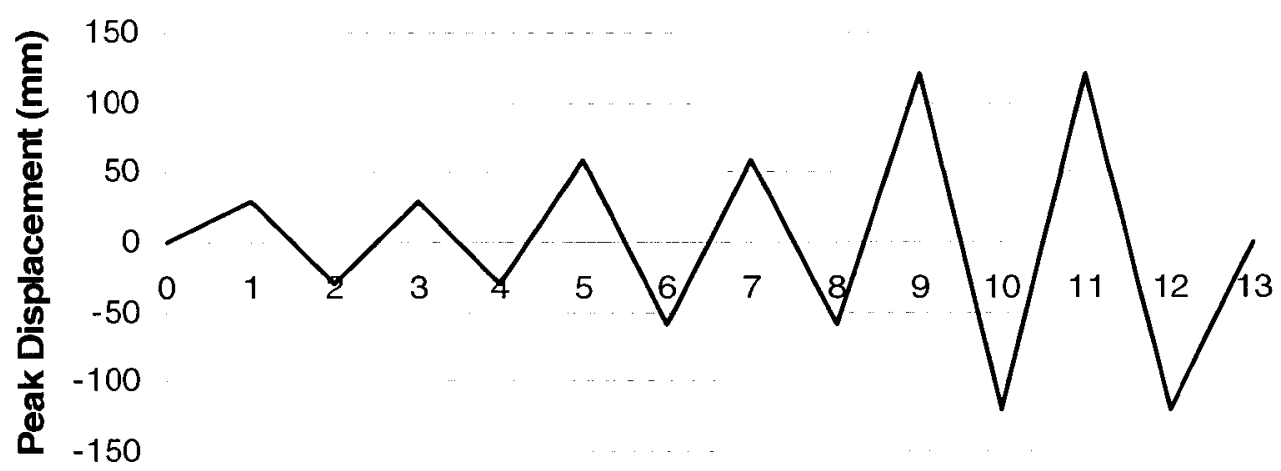

(a)

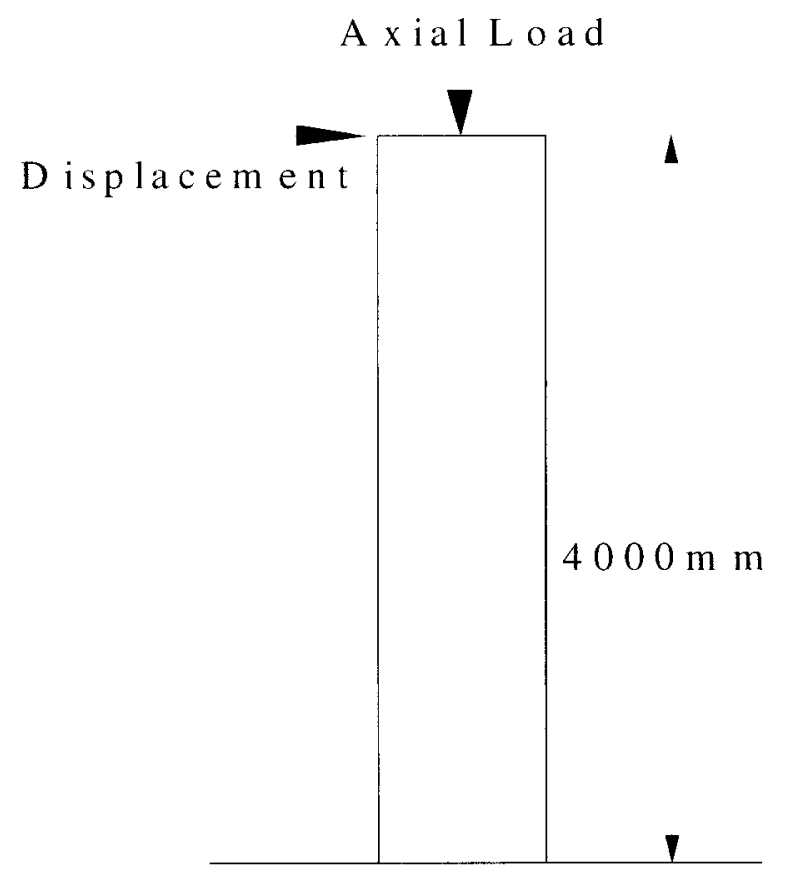

(b)

Figure 2-7 Cyclic simulation on column 


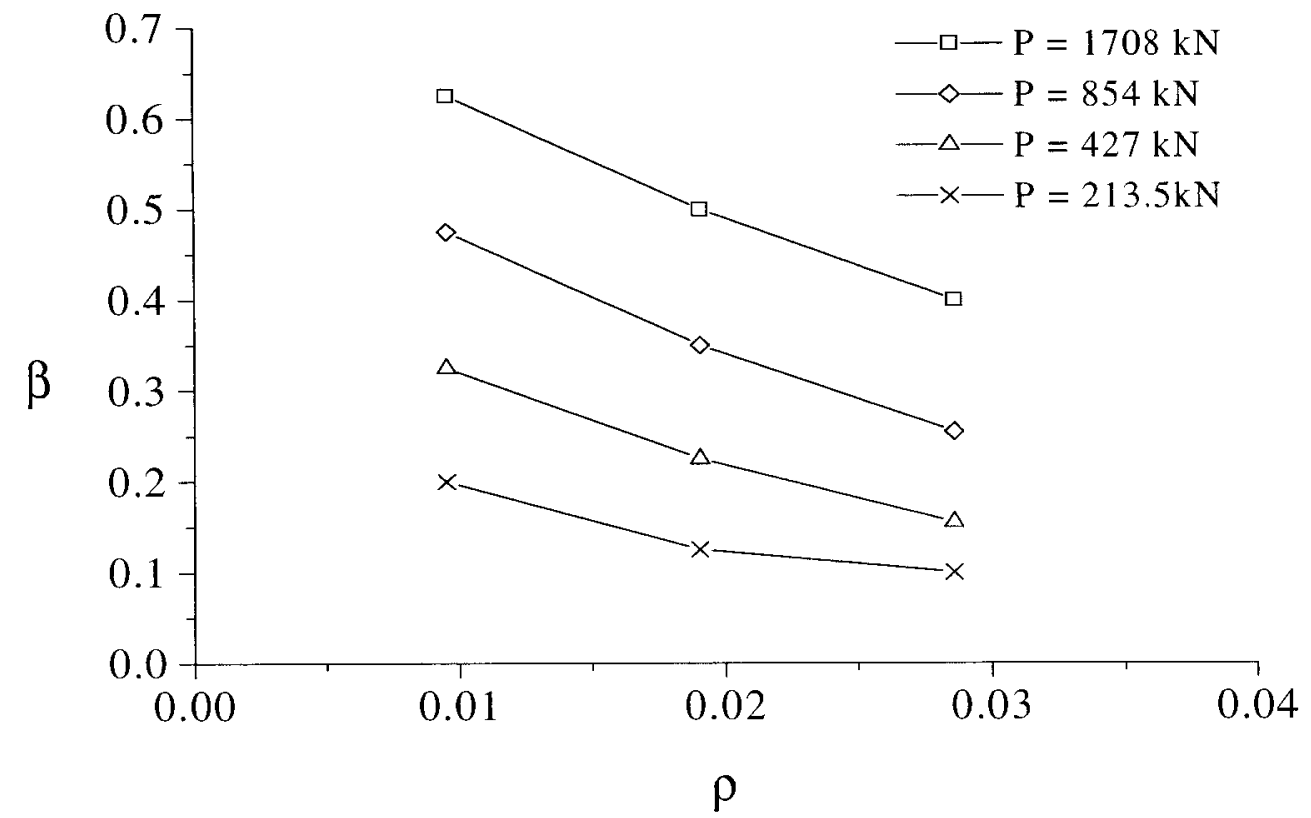

(a) members with cross sectional area and material properties

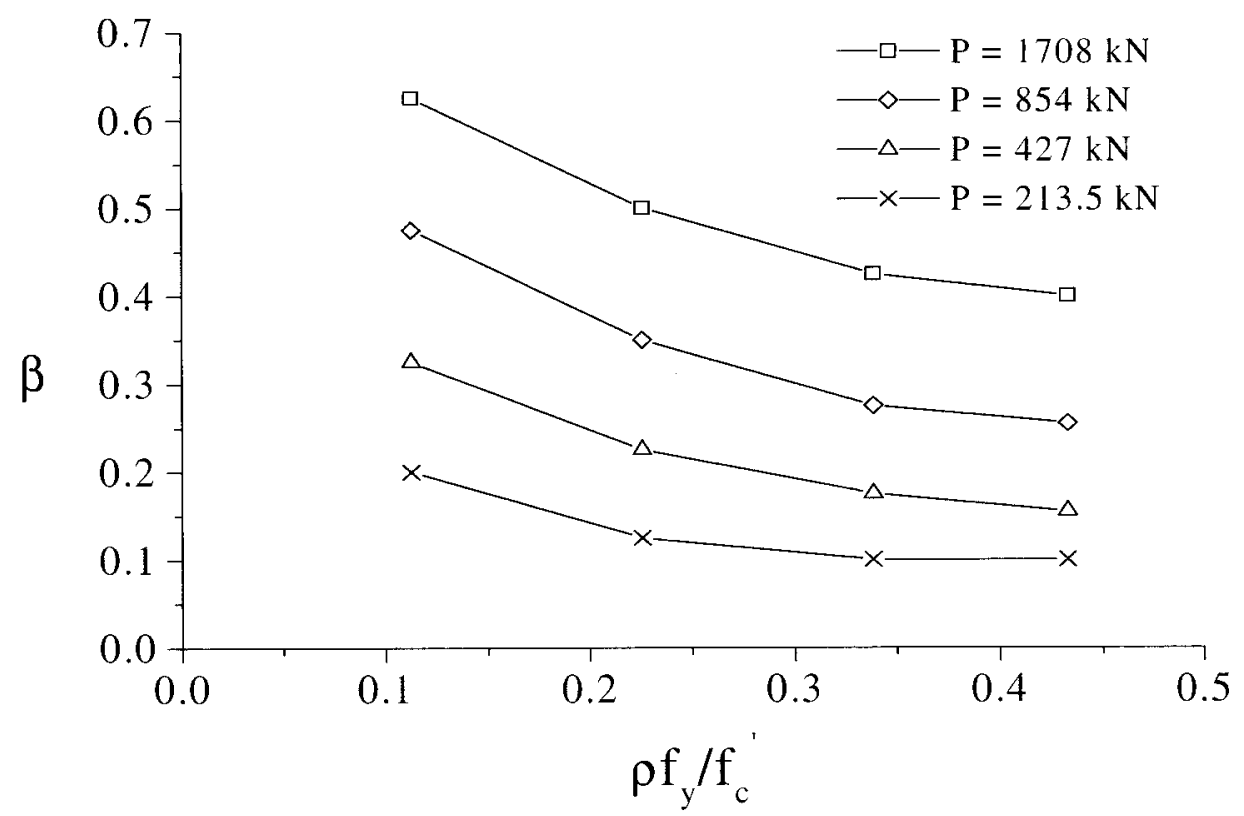

(b) members with same cross sectional area

Figure 2-8 Influence of reinforcement ratio, steel yielding strength and concrete compressive strength on unloading stiffness parameter $\beta$ 


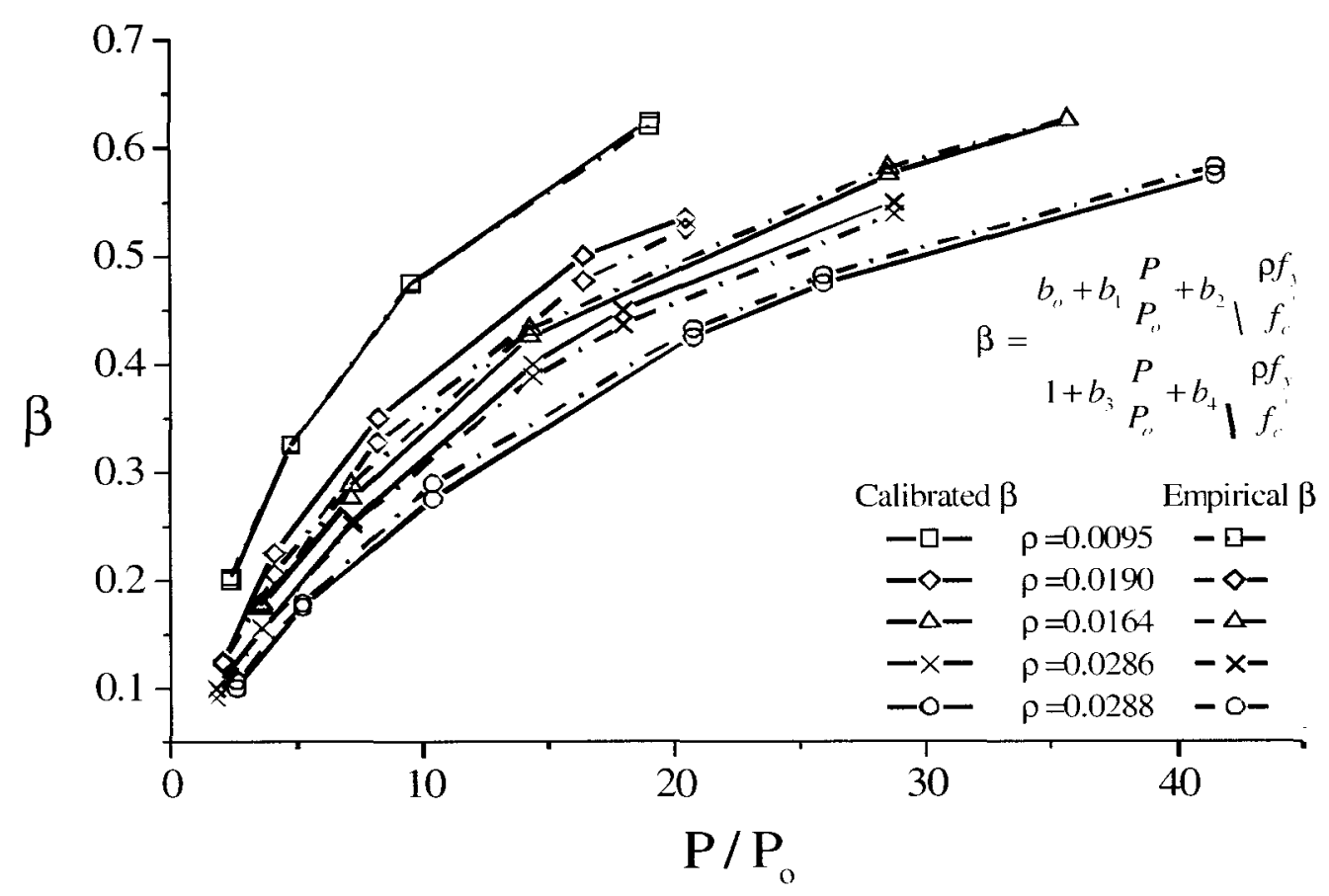

Figure 2-9 Unloading stiffness parameter $\beta$ vs. percentage of axial load $P / P_{0}$ 


\section{Chapter 3 Computer Implementation}

In the present study, computer modules based on the computer-aided toolbox Mathcad have been developed for the implementation of the simplified equivalent analysis model and procedures to generate the required stress-strain relationship of the nonlinear equivalent member material. The developed computer modules can be used in conjunction with other computer structural analysis programs with user specified nonlinear material modeling capacities for detailed analysis nonlinear reinforced concrete structural members of arbitrary shape.

Open System for Earthquake Engineering Simulation framework (OpenSees) (Mazzoni et al. 2005) is a software framework in development at the University of California, Berkeley for simulating the seismic response of structural and geotechnical systems subjected to earthquakes. It has a library of different material and structural element modeling modules, and computational platforms which can be selected and assembled into specific analysis tools for advanced analysis of complex structural systems. In the present study, modules of the simplified method for monotonic loading are implemented in the OpenSees. The hysteretic material model in the OpenSees is adopted and modified for analyzing the behavior of structural members subjected to cyclic loading using the simplified method. The derived equivalent material model adopted for cyclic response 
analysis of reinforced concrete member has the hysteretic relationship as shown in Figure 3-1.

The basis of the equivalent model in modeling the cyclic response behavior of a reinforced concrete member is the equivalent stress-strain relationship derived by the simplified method. As shown in Figure 3-1, point 1 denotes the cracking state of the concrete, point 2 denotes initial yielding of the reinforcing steel, and point 3 is the ultimate strength of the reinforced concrete member. During cyclic loading, the unloading and reloading branches of the hysteretic model are established by the stiffness degradation parameter $\beta$, the pinching effects modeling parameter $c_{1}$ and $c_{2}$, and strength deterioration and softening parameter $D$ as discussed in previous sections.

The unloading path from point 3 to point 4 has an unloading stiffness $K_{u}$. In the reloading, in the opposite loading direction, due to the pinching effect, the load path targets at the pinching reference point 5 , as defined by the pinching parameters $c_{1}$ and $c_{2}$, which range from 0 to 1 . On continuing loading beyond point 5 in the opposite direction, the load path aims toward the yielding point 6 . On unloading from the maximum at point 7 , the response follows with the same unloading stiffness $K_{u}$ toward point 8 . During reloading in the positive direction, the load path targets to the pinching reference point 9 , after which it points towards a reduced maximum response at point 10 because of strength deterioration and softening.

The parameters controlling the hysteretic behavior of the model are presented as follows: 
1. In this study, the unloading stiffness is defined by $K_{u}=K_{o} \cdot\left(\frac{\delta_{m}}{\delta_{y}}\right)^{-\beta}$, and the proposed equation of the unloading stiffness parameter $\beta$ is a function of the percentage of the maximum axial load, the reinforcement ratio, the steel yield strength and the concrete compressive strength as given by Equation (2.20)

$$
\beta=\frac{b_{0}+b_{1} \frac{P}{P_{o}}+b_{2} \sqrt{\frac{\rho f_{y}}{f_{c}}}}{1+b_{3} \frac{P}{P_{o}}+b_{4} \sqrt{\frac{\rho f_{y}}{f_{c}}}}
$$

$b_{0}, b_{1}, b_{2}, b_{3}, b_{4}$ are the constants, which are calibrated by the steel concrete fiber model to be $0.030,14.02,0.151,15.54$ and 7.075 . This empirical expression $\beta$ is used to determine the members unloading stiffness of the numerical example structures subject to cyclic and earthquake loading in this study.

2. As the columns or beams with low shear span ratio (Park and Ang 1985; D'Ambrisi and Fillipou 1999), the pinching effect is considered an important phenomenon in modeling the hysteretic behavior of the reinforced concrete structures. However for the structural members considered for the validation and correlation study here, the shear span ratio are more than 5 , sufficient confinement is provided by the transverse reinforcement in the reinforcing detailing, and both the steel concrete fiber model analysis results and the experimental test results show that the pinching effect does not contribute significantly in the hysteretic 
behavior of the structures. Thus, the values of pinching parameters of $c_{1}$ and $c_{2}$ are set based on the compared experimental results if pinching behavior is observed. However, the capability to model pinching behavior in the hysteretic response is included in the computer implemented models described here.

3. Experiments have shown that the rate of strength deterioration and softening under cyclic loading increase with high axial forces and high lateral deformation (Park et al 1982; Ozcebe and Saatcioglu 1989). Park and Ang (2003) recommended that the value of the damage index $D$ should be calibrated with observed seismic damage of structures, and due to the complexity of the parameters, in the study, the damage index $D$ is set if strength deterioration and soften are observed in the experimental data of the structures. 


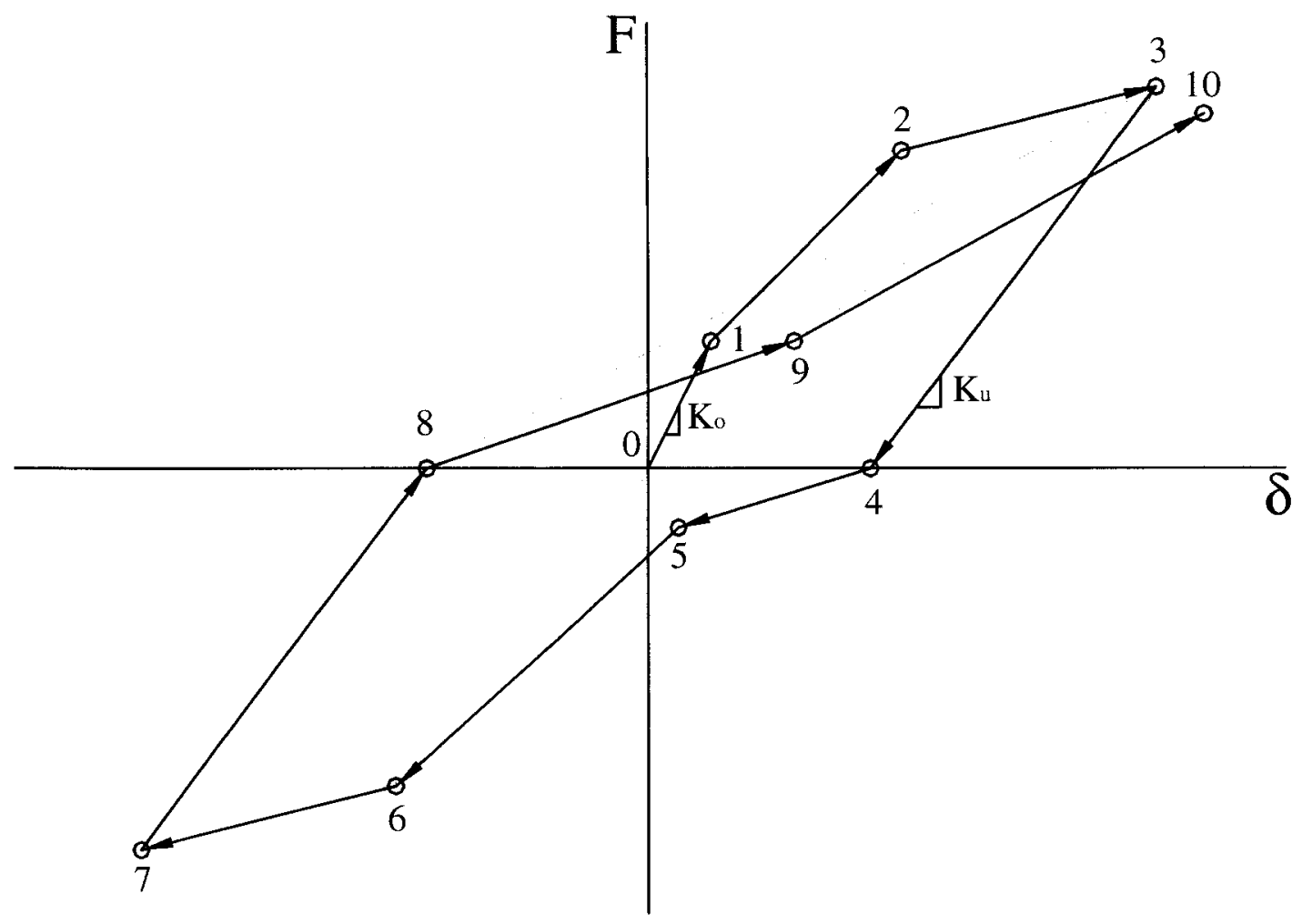

Figure 3-1 Equivalent material model for cyclic loading 


\section{Chapter 4 Numerical Examples}

To demonstrate the validity of the equivalent model and analysis procedure, numerical examples of reinforced concrete structures are analyzed using the simplified method. Two simple structural members, a reinforced concrete cantilever beam and a double-skinned concrete filled tubular (DSCFT) member, which is an innovative system recently developed in Taiwan for seismic construction. Results from the simplified method are compared with the fibre layer model using OpenSees, and finite element model using the computer program ABAQUS. The simplified method results on the DSCFT columns are also compared to experimental test results obtained in experimental research by Tsai et al. (2002). The equivalent model is implemented into OpenSees for analysis of the nonlinear behavior of two full-scale frames. A full-scaled 2-story 2-bay typical reinforced concrete frame (Mazzoni et al. 2005), consisting of reinforced concrete columns and beams, are analyzed by push-over and reversed cyclic loading using steel concrete fiber model and the equivalent model. A full-scaled 3-story 3-bay composite RCS moment frame recently tested by pseudo-dynamic testing procedures (Chen et al 2003 and Cordova et al. 2003), consisting of reinforced concrete columns, steel girders and concrete slabs are analyzed. The stimulation results by the simplified method on the composite frame are compared with the fiber layer model using OpenSees, and with the experimental test results obtained in the pseudo-dynamic tests conducted at NCREE. 


\subsection{Cantilever Beam}

The cantilever beam analyzed in this study is a doubly reinforced concrete structural member with only longitudinal reinforcement subjected to an end applied moment. The rectangular section is reinforced by compression steel $\left(\mathrm{As}^{\prime}=6300 \mathrm{~mm}^{2}\right)$ at an effective depth of $76.2 \mathrm{~mm}$, and tension steel $\left(\right.$ As $\left.=6300 \mathrm{~mm}^{2}\right)$ at an effective depth of $732.8 \mathrm{~mm}$. The compression strength of the concrete is $30 \mathrm{MPa}$ with an ultimate strain of 0.0035 . For the example here, the concrete material is assumed to be unconfined due to the absence of transverse reinforcement, and the steel is modeled by a bilinear model with perfectly plastic behavior after yielding. Table 4-1 and Figure 4-1 show the dimensions and material properties, respectively, of the example cantilever beam.

For the cantilever beam, the derived equivalent stress-strain relationship for the reinforced cantilever beam is presented in Figure 4-2. The direct formulation gives a fluctuating stress-strain relationship, whereas as the strain energy approach gives a smooth equivalent stress-strain relationship. The moment-curvature behavior at the tip of the cantilever beam obtained by the simplified method using ABAQUS are shown in Figure 4-3. From comparison of the numerical results show in Figure 4-3, it is observed that the equivalent stress-strain relationship obtained by the energy approach results in a lower yielding capacity of the equivalent model. The strain energy of the equivalent member by the energy approach closely follows the behavior of the original reinforced concrete member. This is particularly noticeable for response after the elastic limit. In comparison, the results by the direct formulation give fluctuating behavior in the moment-curvature relationship in the inelastic ranges. Thus, the results indicate that the 
simplified method by the energy approach can accurately predict the behavior of the cantilever beam up to the ultimate capacity. It is noted that since the concrete material in the cantilever beam is unconfined, therefore large portion of the concrete material does not contribute to the resistance of the load when the strain of the concrete fiber exceeds 0.002. Consequently, this leads to a softening behavior in its moment capacity and the behavior of the cantilever beam is governed by the model for the reinforcing steel.

\subsection{Double-Skinned Concrete Filled Tube Member}

Figure 4-4 shows the DSCFT member consisting of two concentric circular thin steel tubes with concrete filled between them. Research carried out in Taiwan (Lin 2002 and Tsai et al. 2002) has demonstrated that the DSCFT members possess light-weight, moderated axial capacity and high flexural strength characteristics. An important advantage of the DSCFT column system is that the reduced weight of the column can lead to a significant reduction of seismic force on the member. Therefore, DSCFT is an innovative structural system particularly suitable for construction of tall bridge priers in seismic regions. Since the DSCFT is a complex reinforced concrete structural system, it is difficult to analyze using general analysis methods. The simplified method is applied here to analyze the behavior of the DSCFT.

The experimental specimen analyzed using the simplified approach has an effective length of $1100 \mathrm{~mm}$. The external and internal tube diameters are $300 \mathrm{~mm}$ and $180 \mathrm{~mm}$, respectively. The thickness is $2 \mathrm{~mm}$ for both the external and internal steel tubes. Table 4 - 
2 lists the material properties used in the analysis. For the case study here, the concrete filler is initially modeled as confined concrete with confinement coefficient $\mathrm{k}$ of 1.231 , as determined by the modified Kent and Park confined concrete model for the amount of steel in the double skinned steel tube. A bilinear model is adopted for representing the behavior of the steel tube material.

Figure 4-5 shows the comparison of the derived stress-strain relationships by the direct formulation and the strain energy formulation of the simplified method. Figure 4-6 shows the comparison of the numerical results of the moment-curvature behavior obtained by the equivalent model implemented in OpenSees using the derived stress-strain relationships from the simplified method, and test results from the experiments conducted by Tsai et al. (2002). When comparing with the experimental results, the simplified method gives a conservative lower moment capacity. One possible reason for the lower moment capacity is due to the inadequate modeling of strength and stiffness of the confined concrete core. To more accurately account for the total confinement of the concrete core by the steel tubes, a parametric study on the confinement coefficient $\mathrm{k}$ is carried out by increasing $\mathrm{k}$ to 2.5 and 3.7 , which are twice and three times of that determined by the modified Kent and Park model developed for open spiral transverse reinforcement. This means that the confinement of the double skinned steel tube is three times more efficient in providing confinement to the core concrete than open transverse reinforcement assumed in the modified Kent and Park confined concrete model. The results from Figures 4-5 and 4-6 show that the confinement behavior of the concrete core 
due to the double skinned steel tubes is more accurately represented by the confinement coefficient $\mathrm{k}=3.7$.

Figure 4-7 shows the comparison of the analytical results obtained by OpenSees based on the derived stress-strain relationship of the equivalent member material with the confinement coefficient $\mathrm{k}=3.7$ and test results from the experiments conducted by Tsai et al. (2002). It is observed that the simplified model consistently gives a conservative lower moment capacity, with the proposed empirical $\beta$, the simulated unloading behavior of the DSCFT is in good correlation with the experimental results. The pinching effect and the ultimate moment capacity predicted by the computer simulation agree reasonably well with the test data. Beyond the peak moment, the actual behavior of strength and softening of the DSCFT member decays much rapidly than the equivalent model in this example.

\subsection{2-Story 2-Bay Reinforced Concrete Frame}

To calibrate the parameters of the equivalent model implemented in OpenSees for the analysis of nonlinear behavior of the reinforced concrete structures, a full-scaled 2-story 2-bay RC frame (Mazzoni et al. 2005) are analyzed for push-over and cyclic loading simulations. The frame consists of reinforced concrete columns and beams, as shown in Figure 4-8, with a typical width of the bay $7000 \mathrm{~mm}$ and a typical story height of $4000 \mathrm{~mm}$. The material properties and the dimensions of the structural member sections are presented in Tables 4-3. 
Simulation of the static push-over and cyclic loading behavior are carried out using the steel concrete fiber model and the equivalent model for calibration of the modeling parameters in the equivalent model. Such as those for modeling the axial load influence, pinching behavior and strength deterioration and softening as discussed earlier. For both models, the frame members are modeled in OpenSees by the flexibility-based nonlinear beam-column fiber element, which is based on the non-iterative force formulation and the spread of plasticity along the element. This allows the columns and beams to be modeled by a single element without discretizaiton error in computation (Neuechofer and Fillipou 1997). Three fiber sections are considered in modeling the exterior columns, the interior columns and the beam. In the simulation of using the steel concrete fiber model, the material models are employed steel02 and concrete01. An equivalent member of homogeneous material properties is derived by the simplified method for each frame member in the simulation by the equivalent model.

In the push-over simulation, a lateral displacement control iteration scheme of a linear time series is considered to generate the behavior of the frame. As shown in Figure 4-8, a lateral load pattern of a distribution ratio of $2: 1$ at the second and first floor levels of increasing magnitude, and a gravity load pattern of a distribution ratio of $2: 1$ at the first and second floor levels, as well as the nodes of the interior columns and the exterior columns, are applied to the frame for the push-over analysis. In the cyclic loading simulation, a lateral displacement control iteration scheme also is used, and the cyclic loading pattern is shown in Figure 4-9. The gravity loads distribution of the frame under 
cyclic loading is assumed to be the same as that considered in the static push-over analysis.

Figure 4-10 presents the results of the push-over analyses of the 2-story 2-bay RC frame by the steel concrete fiber model and the equivalent model. It is observed the equivalent model results, considering axial load influence in modeling the hysteretic behavior on the unloading stiffness, the nonlinear behavior of the frame structures can be captured well. The equivalent model results give a slightly conservative lower strength capacity of the reinforced concrete frame. The discrepancy between the analysis results by two different modeling methods of steel concrete fiber model and the equivalent model is possibly due to the approximation in evaluating the accumulated strain-energy loss in the derivation of the equivalent stress-strain relation for the equivalent member. In the cyclic loading simulation, the empirical expression $\beta$ is used to compute the unloading stiffness of the equivalent members, along with the pinching modeling parameters $c_{1}$ and $c_{2}$, and the strength deterioration and softening parameter $D$. As shown in Figure 4-11, the simulation results of the 2-story 2-bay RC frame under reversed cyclic loading by the equivalent model agree well with the results by the steel concrete fiber model. The major characteristics in the hysteretic behavior of reinforced concrete frame under cyclic loading are captured, such as the initial loading stiffness, the maximum deformation at each loading cycle, the stiffness degradation at unloading, and the pinching effect in reloading. 


\subsection{3-Story 3-Bay Reinforce Concrete-Steel Frame}

For further validation of the accuracy and modeling capability of the equivalent model of reinforced concrete frame simulation under earthquake loading, a correlation study is carried out to compare the simulation results with the test data obtained by Chen et al. (2003) at the National Center of Research on Earthquake Engineering (NCREE) on a fullscale 3-story 3-bay RCS frame, as shown in Figure 4-12. The full-scale tested 3-story 3bay RCS frame consists of reinforced concrete columns, steel girder and concrete slab, with a typical bay width of $7000 \mathrm{~mm}$ and a typical story height of $4000 \mathrm{~mm}$. This type of strong-column weak-beam composite frame can provide efficient and economics alternatives to traditional steel or concrete construction by effective use of materials, and provide high strength, stiffness, and ductility (Lee and Pan 2001; Chen et al. 2003; and Cordova et al. 2003). The columns of second and third floor are spliced using mechanical sleeves on the top of the slabs, and the columns of first floor are spliced $1000 \mathrm{~mm}$ from the top of the footings. Each composite beam has two bolted splices. The design and construction details of the full-scale 3-story 3-bay RCS frame can found in Chen et al. 2003 and Cordova et al. 2003. The full-scale 3-story 3-bay RCS frame was tested and loaded pseudo-dynamically at NCREE to monitor the structural response under ground motions obtained by scaling the Chi-Chi ground motion record to the earthquake hazard level corresponding to $50 \%, 10 \%$, and $2 \%$ chance of exceeding in 50 years. The first test results of $50 \%$ chance of exceeding in 50 years are compared with the simulation results using of the equivalent model implemented in OpenSees, as well as the results of the steel concrete fiber model. The acceleration time history of the Chi-chi event of $50 \%$ chance of exceeding in 50 years (before scaling) used in the simulation is shown in Figure 4-13. 
The simulations are conducted using two models, one is the steel concrete model, and the other is the equivalent model in OpenSees. For both models, the frame members are modeled in OpenSees by the flexibility-based nonlinear beam-column fiber element. Experiments and analysis results show that the joints within this RCS frame are inherently strong, and are not expected to experience any significant deformations, and the calibration of the joint elements are less important than the columns and beams (Cordova et al 2003). In the simulation using the steel concrete fiber model and equivalent model in OpenSees, the modeling approaches are the same as the 2-story 2bay RC frame, except that the composite beam is modeled by steel girder and concrete slab. The effective width of the slab is equal to the width of the column and the effective height of the slab is the average thickness of the slab. The material properties and the hysteretic parameters are given in Table 4-4.

According to the experimental data reported by Chen et al. (2003) and Cordova et al. (2003), the composite frame experienced damages, including slippage of the beam splice, cracks in the columns, slabs and beam-column joints, some flaking was also observed in the beam flanges and webs, and there was indication of bond slippage at the base during the ground excitation loading test of Chi-Chi 50/50. Figure 4-14 shows measured roof displacement behavior in the NCREE test and comparison with the simulation results by the steel concrete fiber model and the equivalent model. The simulations results correlate well with the experimental data, expect that after the intensive shaking of about 27 seconds, the roof displacement of the frame from experimental data is larger than the simulation results. This is probably due to the initial damages already sustained by the 
frame in some preliminary tests as reported Chen et al. (2003) and Cordova et al. (2003), resulting in the immediate deterioration and softening in the frame capacity after the intensive loading during earlier part of the loading time history in the actual structure in the experiment which is not duplicated in the computer model simulation results here. Figure 4-15 shows the corresponding base shear results of the experimental test and simulation behavior by the steel concrete fiber model and the equivalent model. The equivalent model can effectively capture the major characteristics in the earthquake response behavior of the frame very well, as well as the more time consuming steel concrete fiber model. Either the equivalent model or the steel concrete fiber model slightly overestimates the base shear response of the frame. The discrepancies between the experimental data and the simulation results are again attributed to the damages indicated by Chen et al. (2003) and Cordova et al. (2003) on the structure components, the bucking of the longitudinal reinforcement of the reinforced columns and the local bucking of the steel beam causing the stiffness decay. In the OpeenSees, the behavior of columns splice and the bolted splice are not modeled which may contribute to some dissipation of the seismic energy in the actual frame. The stiffness of the actual frame could have been decayed by the damage, thus the actual experimental data give larger displacement after intensive excitation period and smaller base shear. 
Table 4-1 Material properties of cantilever beam

\begin{tabular}{cccc}
\hline & Concrete & & Steel \\
Parameter & Value & Parameter & Value \\
\hline$E_{c}$ & $24648 \mathrm{MPa}$ & $E_{s}$ & $200000 \mathrm{MPa}$ \\
$f_{c}^{\prime}$ & $30 \mathrm{MPa}$ & $f_{y}$ & $400 \mathrm{MPa}$ \\
$f_{c r}^{\prime}$ & $3.286 \mathrm{MPa}$ & $f_{u}$ & $400 \mathrm{MPa}$ \\
$\varepsilon_{c}$ & 0.002 & $\varepsilon_{u}$ & 0.10 \\
\hline
\end{tabular}

Table 4-2 Material properties of DSCFT member

\begin{tabular}{cccc}
\hline \multirow{2}{*}{ Concrete } & Value & Parameter & Steel \\
Parameter & $25045 \mathrm{MPa}$ & $E_{s}$ & $201000 \mathrm{MPa}$ \\
\hline$E_{c}$ & $28 \mathrm{MPa}$ & $f_{y}$ & $305.2 \mathrm{MPa}$ \\
$f_{c}$ & $3.175 \mathrm{MPa}$ & $f_{u}$ & $416.1 \mathrm{MPa}$ \\
$f_{c r}^{\prime}$ & 0.002 & $\varepsilon_{u}$ & 0.10 \\
$\varepsilon_{c}$ & \multicolumn{4}{c}{0.05} \\
\hline \multicolumn{4}{c}{ Hysteretic parameters in equivalent model } \\
\hline $\mathrm{D}$ & 0.425 & $\mathrm{c}_{1}$ & 0.05 \\
\hline
\end{tabular}


Table 4-3 Dimension and material properties of the 2-story 2-bay RC frame members

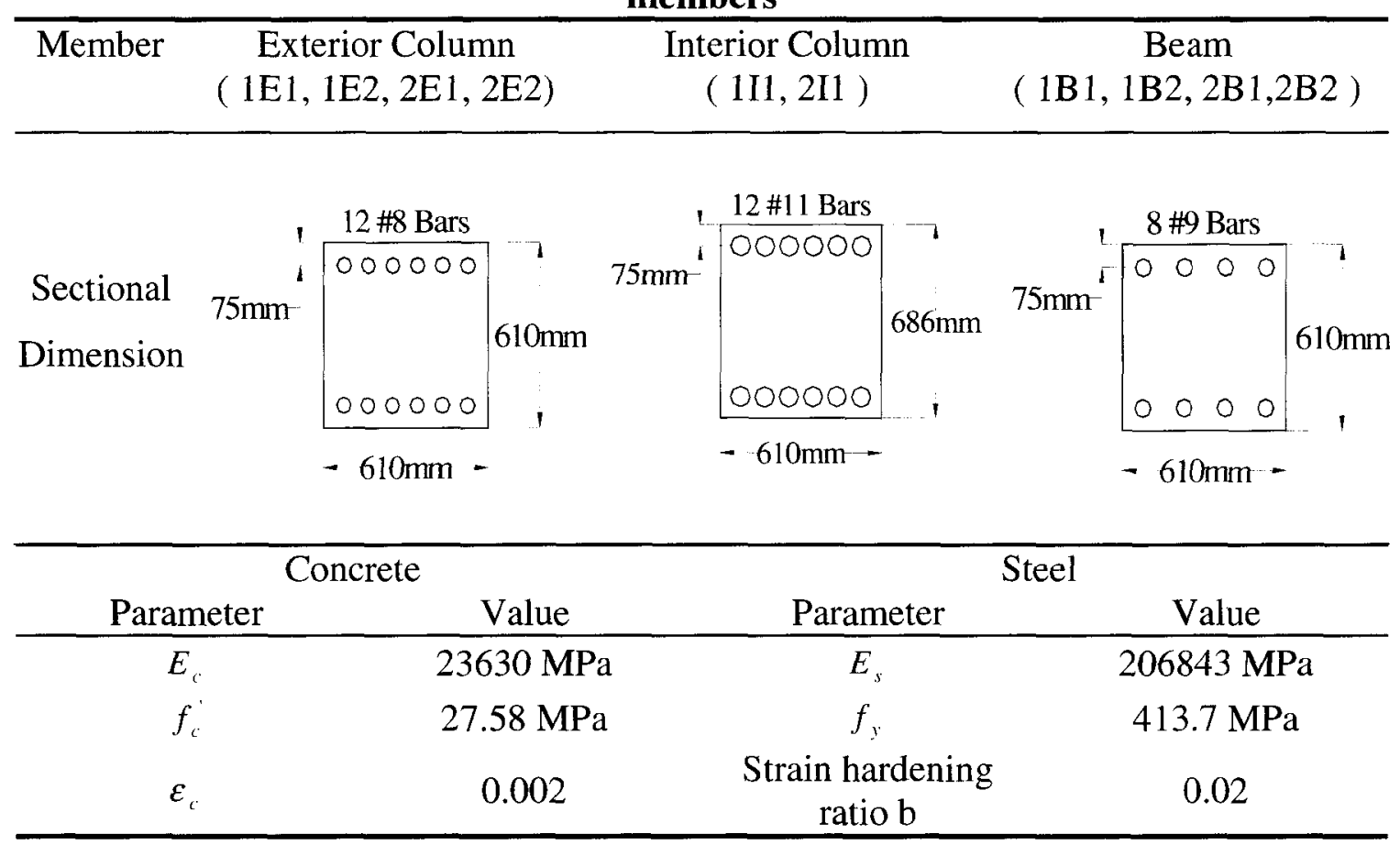

Hysteretic parameters in equivalent model

\begin{tabular}{ccccc}
\hline & $\beta$ & $c_{1}$ & $c_{2}$ & $D$ \\
$1 \mathrm{E} 1$ & 0.425 & 0.0 & 0.0 & 0.0 \\
$1 \mathrm{E} 2$ & 0.425 & 0.0 & 0.0 & 0.0 \\
$2 \mathrm{E} 1$ & 0.275 & 0.0 & 0.0 & 0.0 \\
$2 \mathrm{E} 2$ & 0.275 & 0.0 & 0.0 & 0.0 \\
$1 \mathrm{I} 1$ & 0.425 & 0.0 & 0.0 & 0.0 \\
$2 \mathrm{I} 1$ & 0.275 & 0.0 & 0.0 & 0.0 \\
1B1 & 0.275 & 0.0 & 0.0 & 0.0 \\
1B2 & 0.275 & 0.0 & 0.0 & 0.0 \\
2B1 & 0.275 & 0.0 & 0.0 & 0.0 \\
2B2 & 0.275 & 0.0 & 0.0 & 0.0 \\
\hline
\end{tabular}


Table 4-4 Dimension and material properties of the 3-story 3-bay RCS frame members

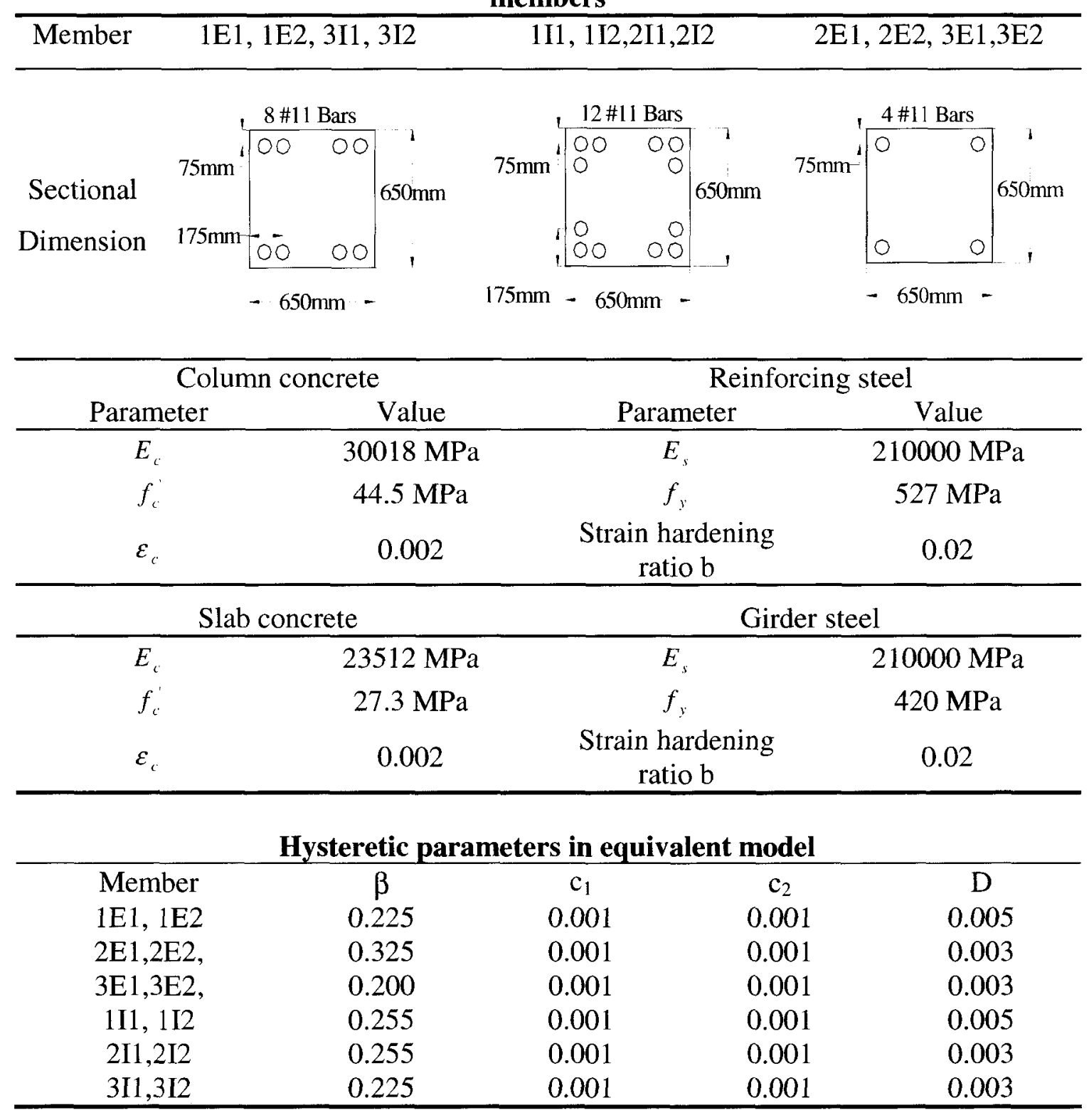




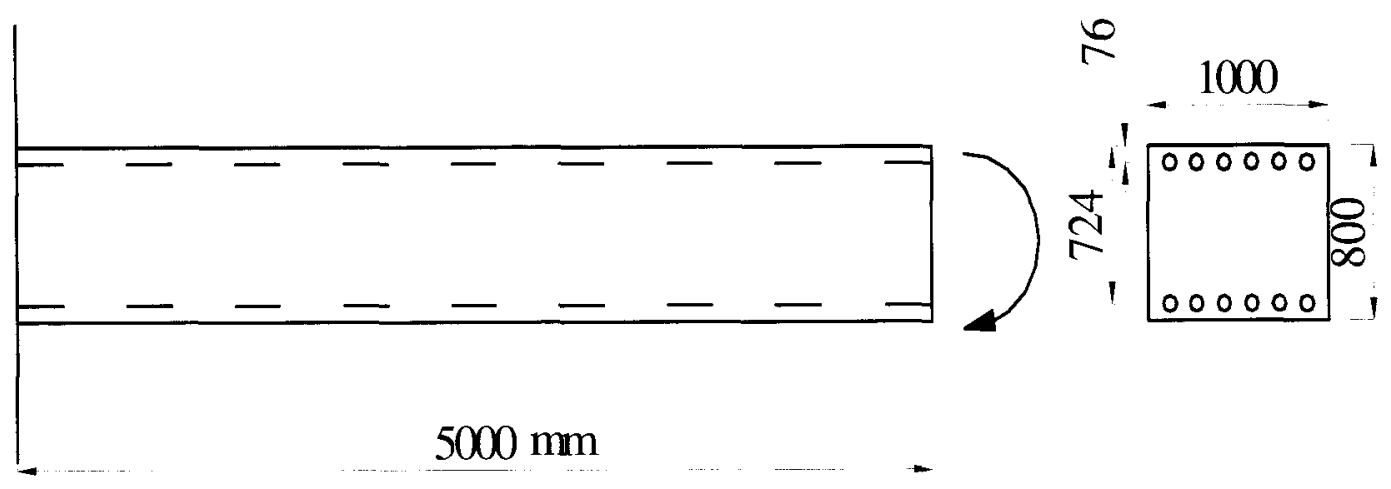

Figure 4-1 Reinforced concrete cantilever beam 


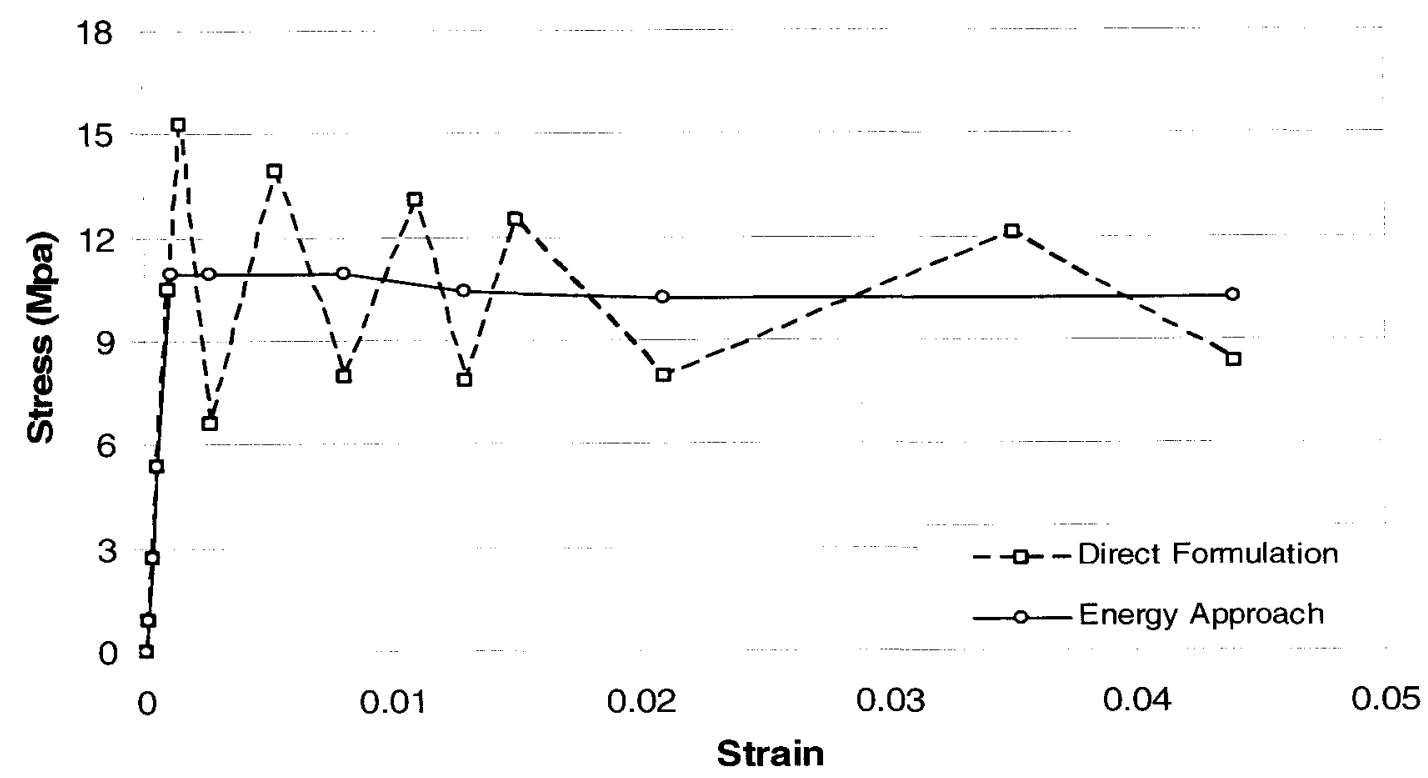

Figure 4-2 Equivalent stress-strain relationship of cantilever beam 


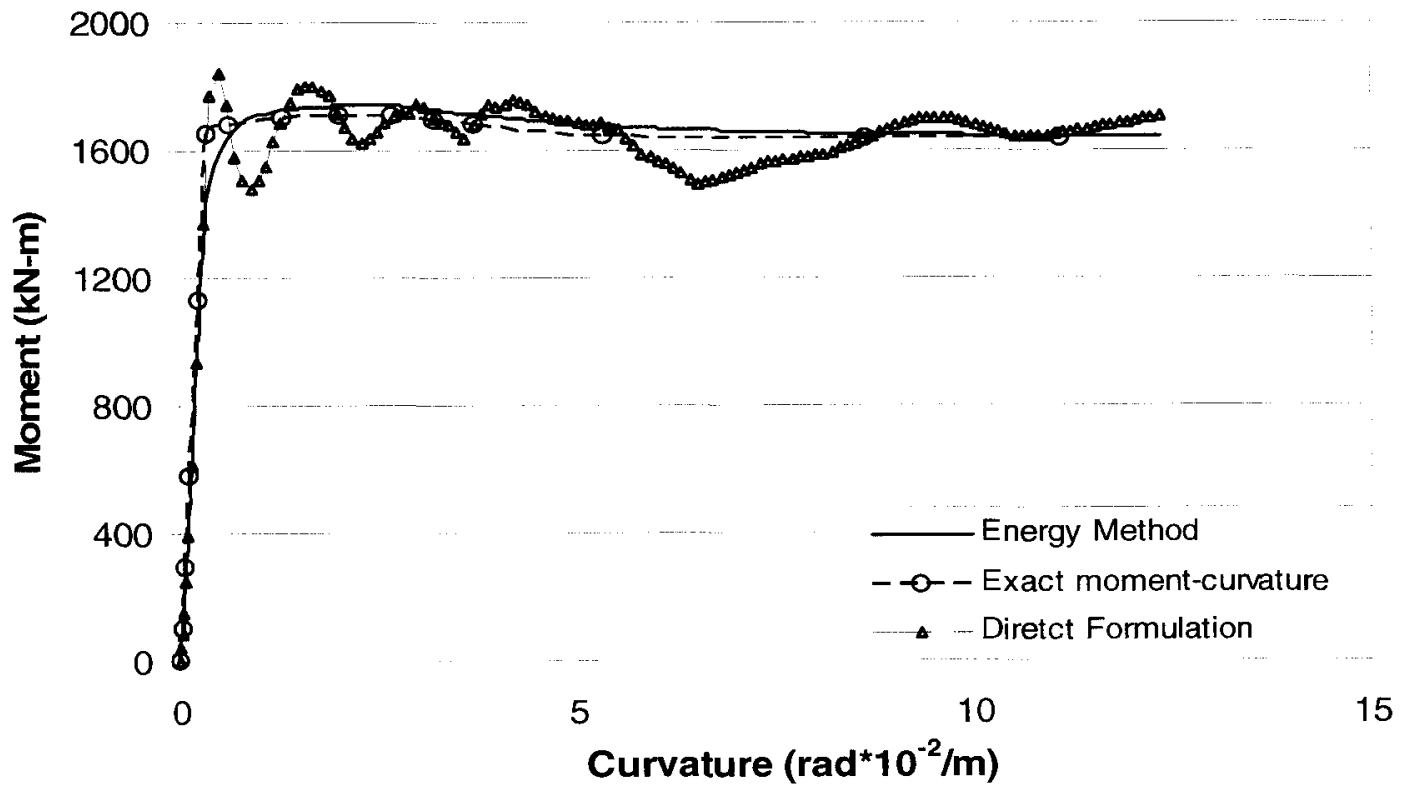

Figure 4-3 Moment-curvature relationship of cantilever beam 

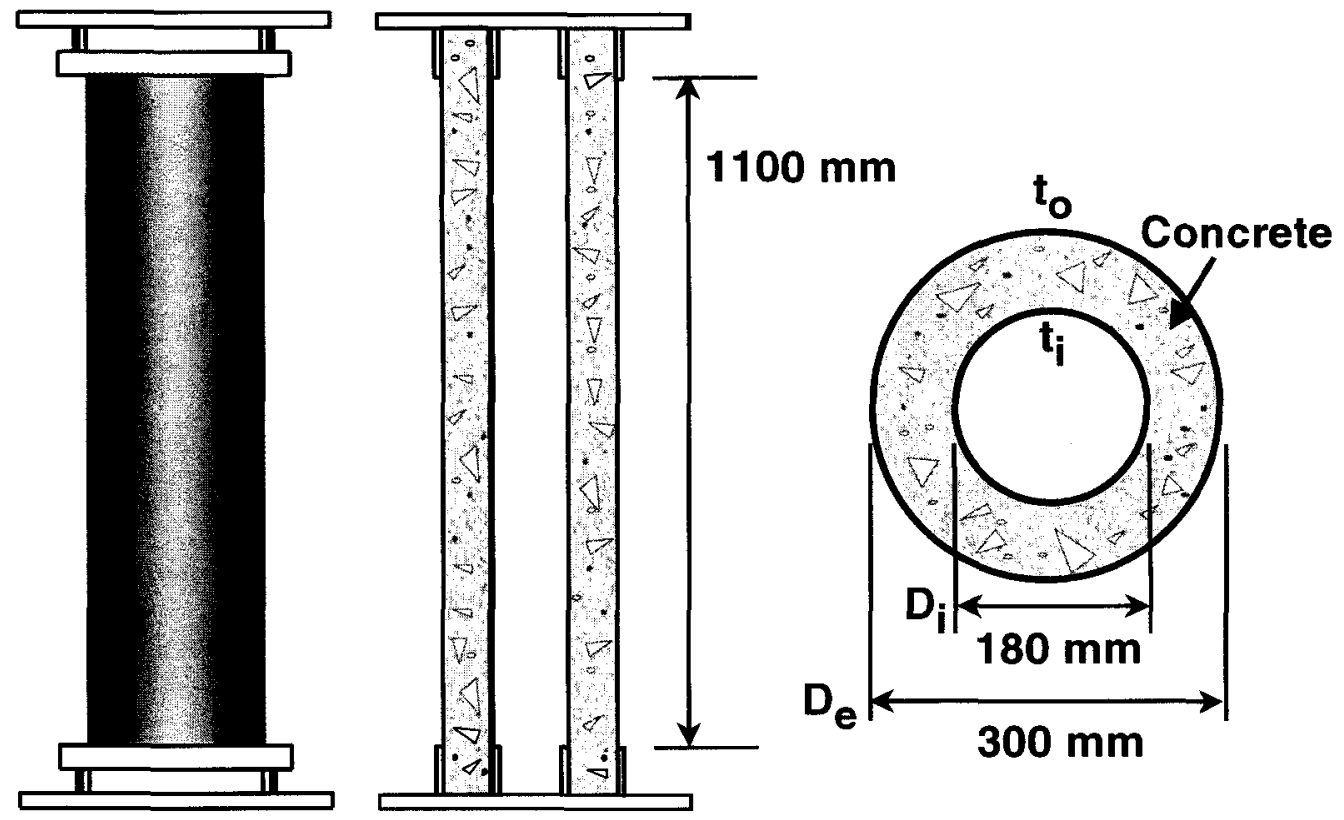

Figure 4-4 DSCFT member (Tsai, 2002) 


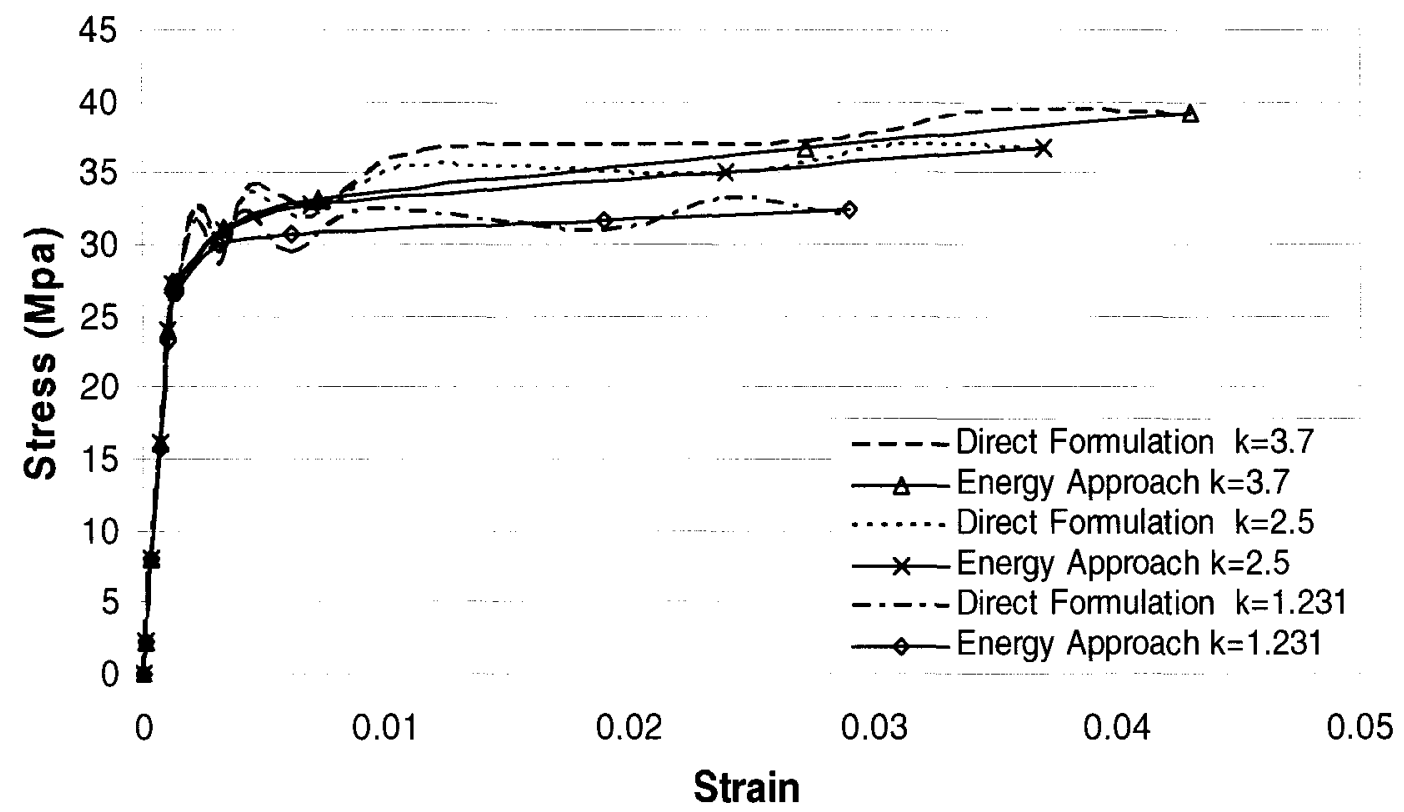

Figure 4-5 Equivalent stress-strain relationship of DSCFT member 


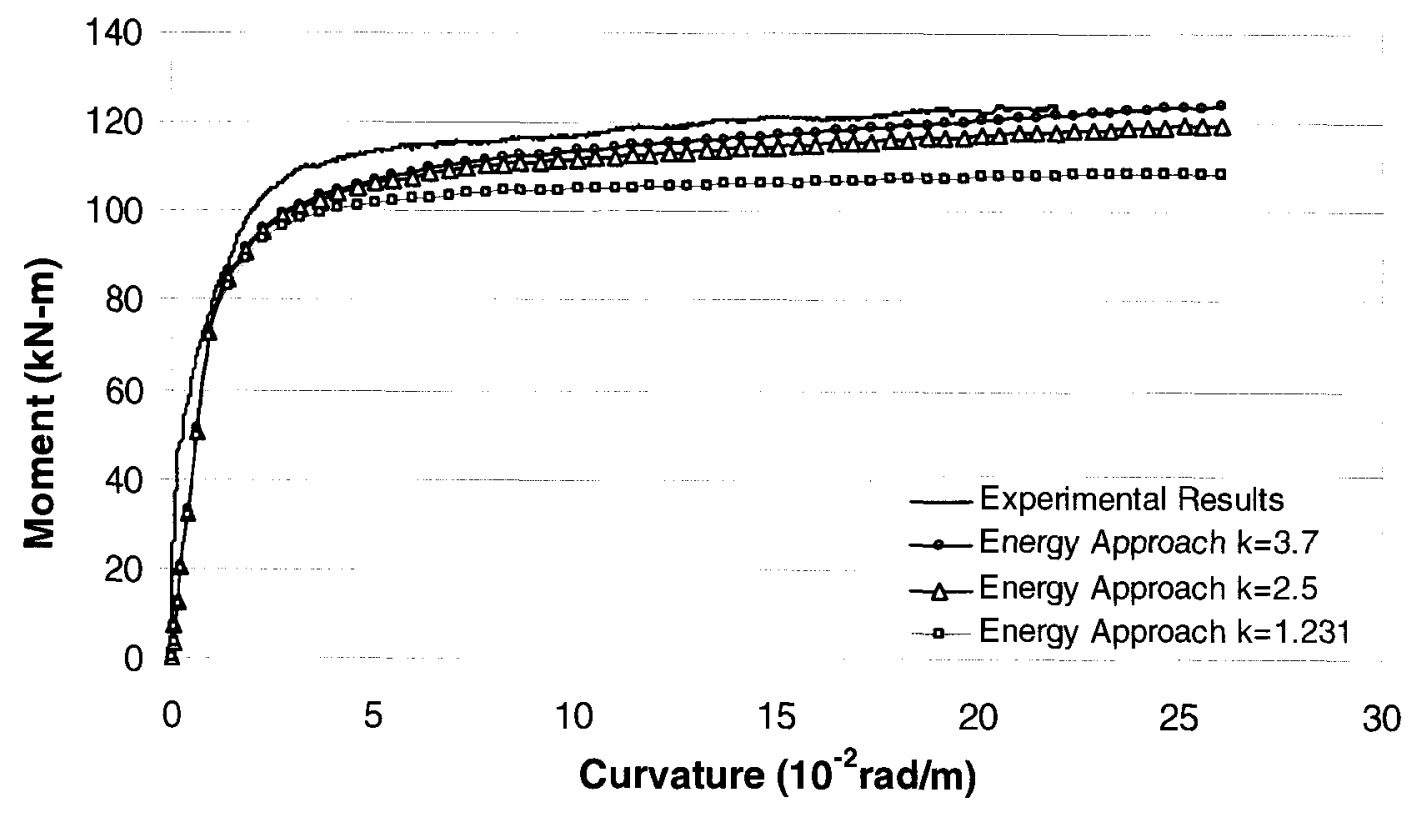

Figure 4-6 Moment-curvature relationships of DSCFT member 


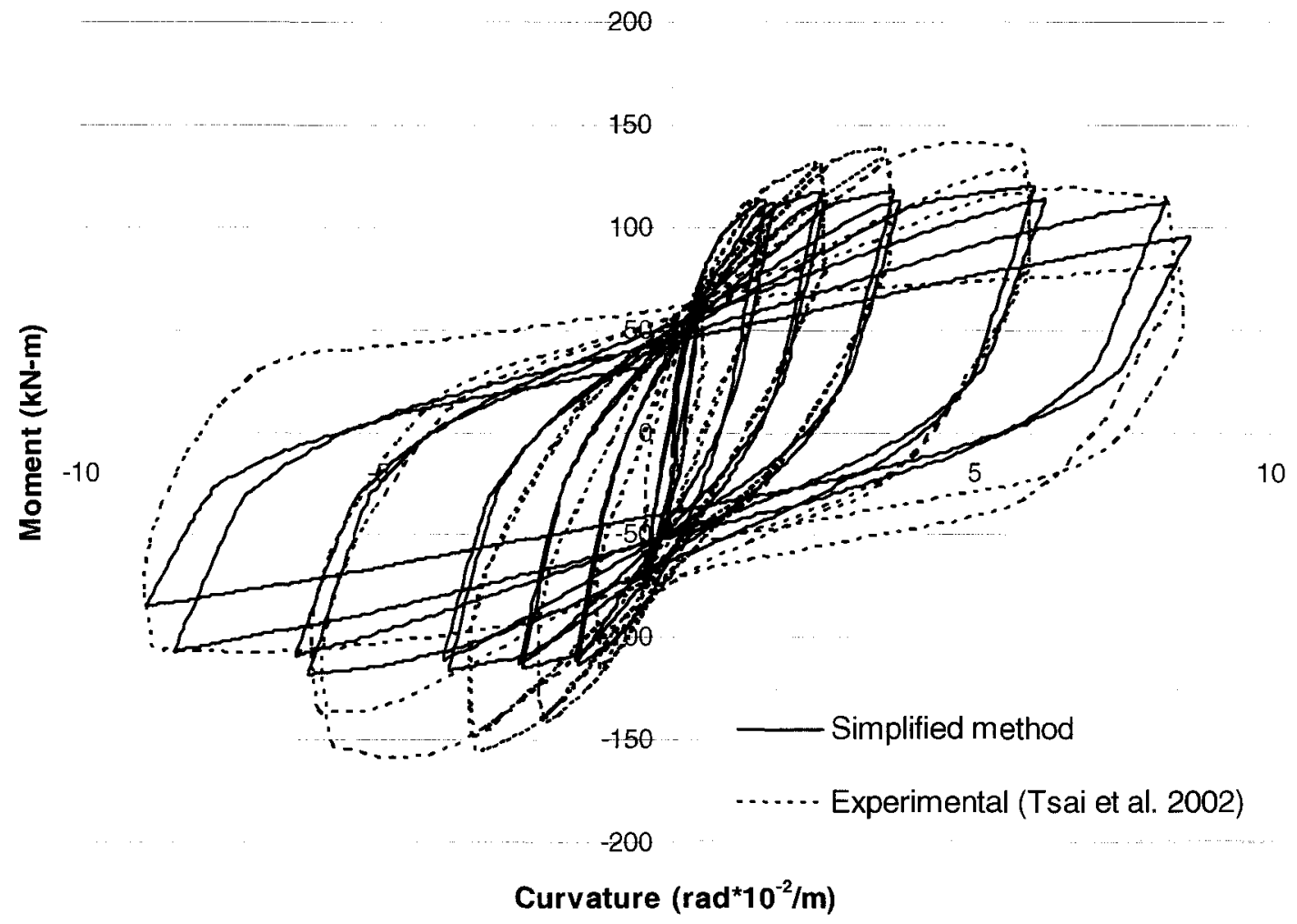

Figure 4-7 Results of cyclic loadings for DSCFT member 


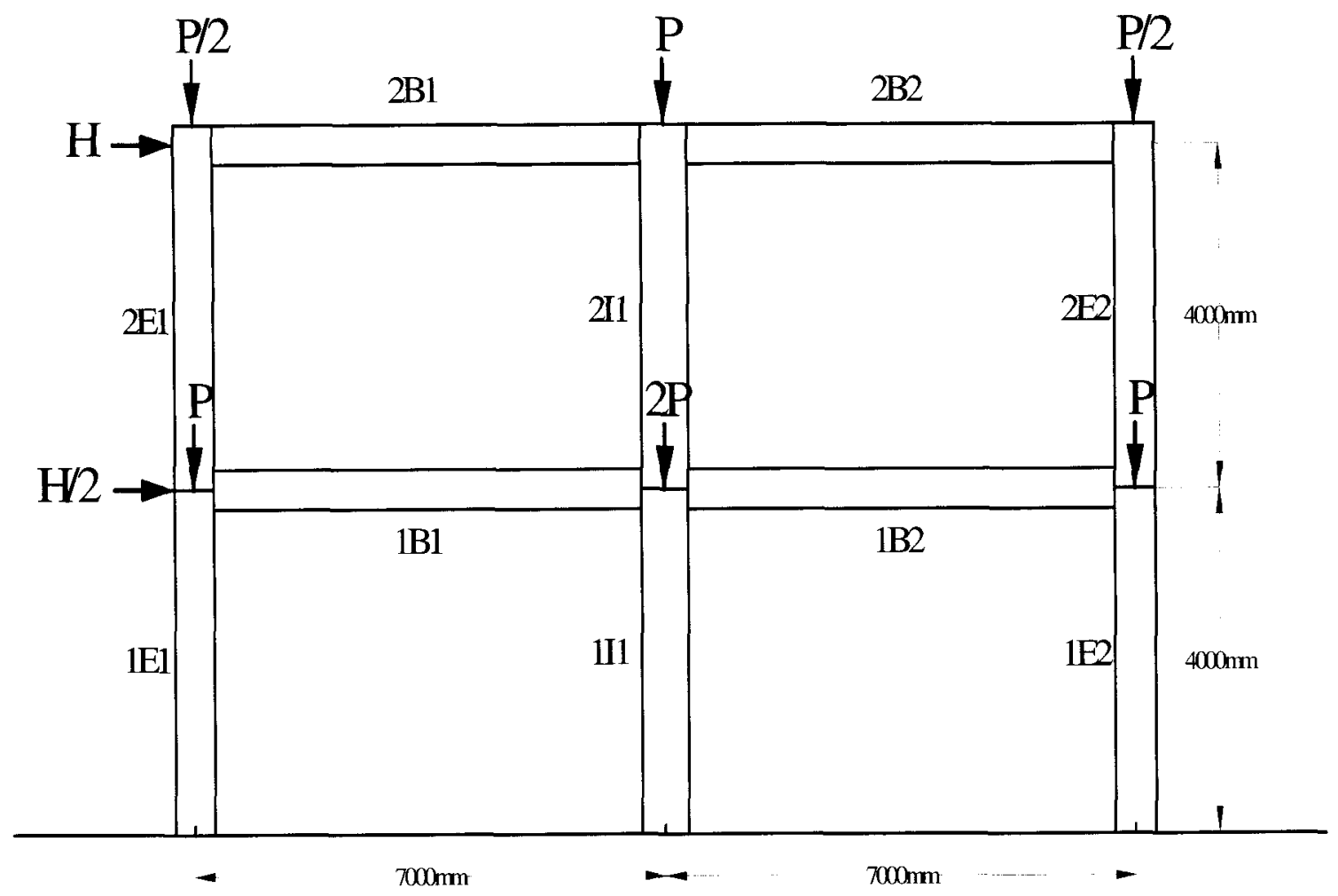

Figure 4-8 2-story 2-bay reinforced concrete frame 


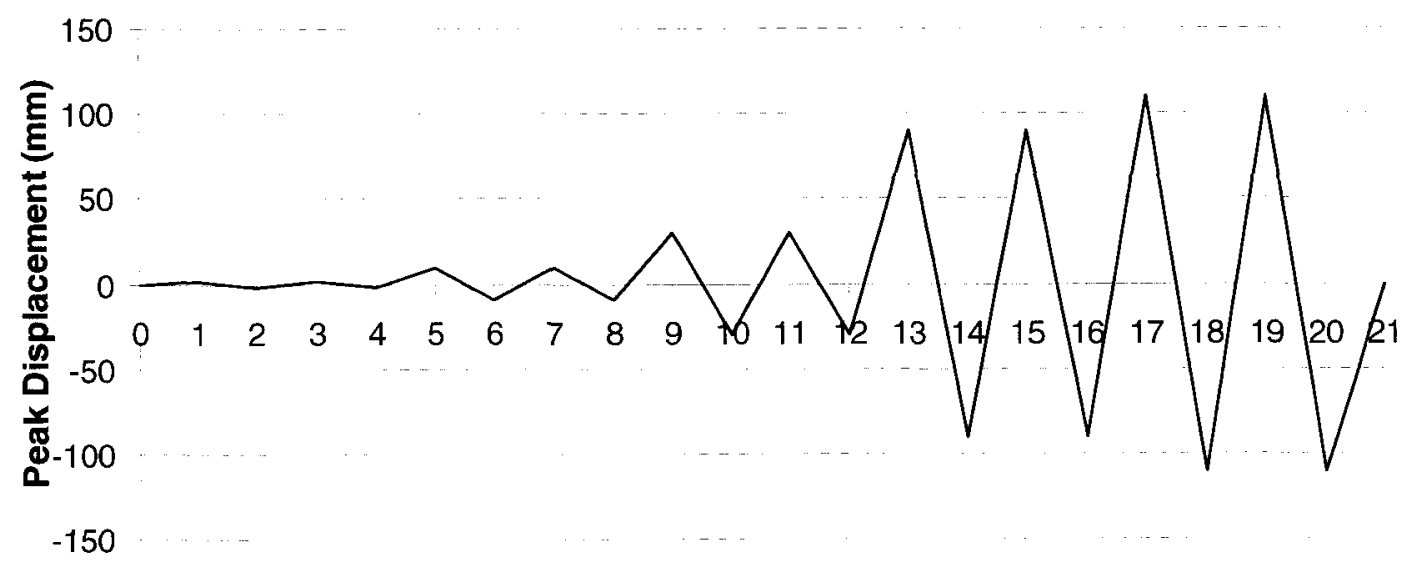

Figure 4-9 Cyclic loading pattern for 2-story 2-bay reinforced concrete frame 


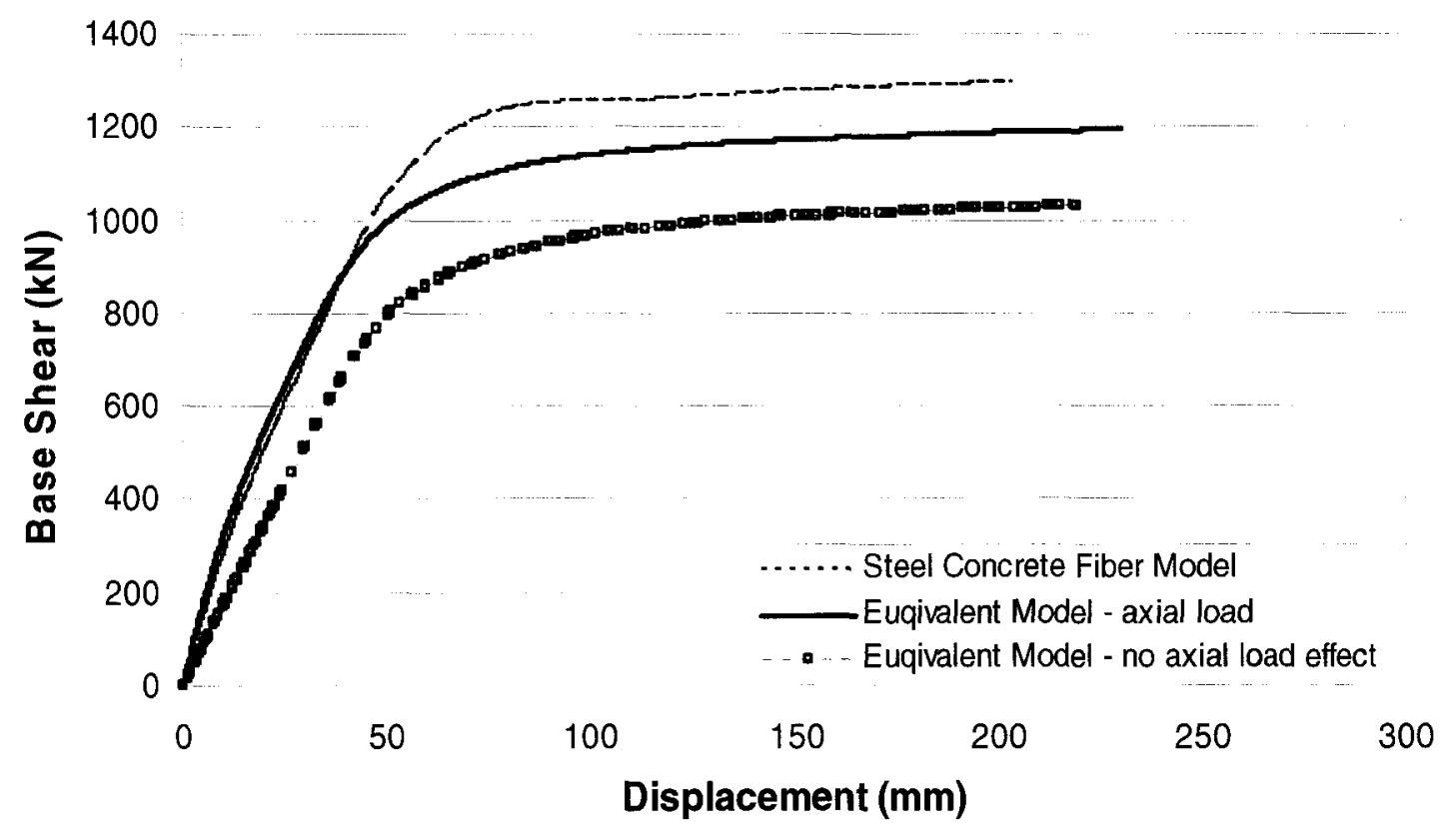

Figure 4-10 2-Story 2-Bay reinforced concrete frame push over simulation results 


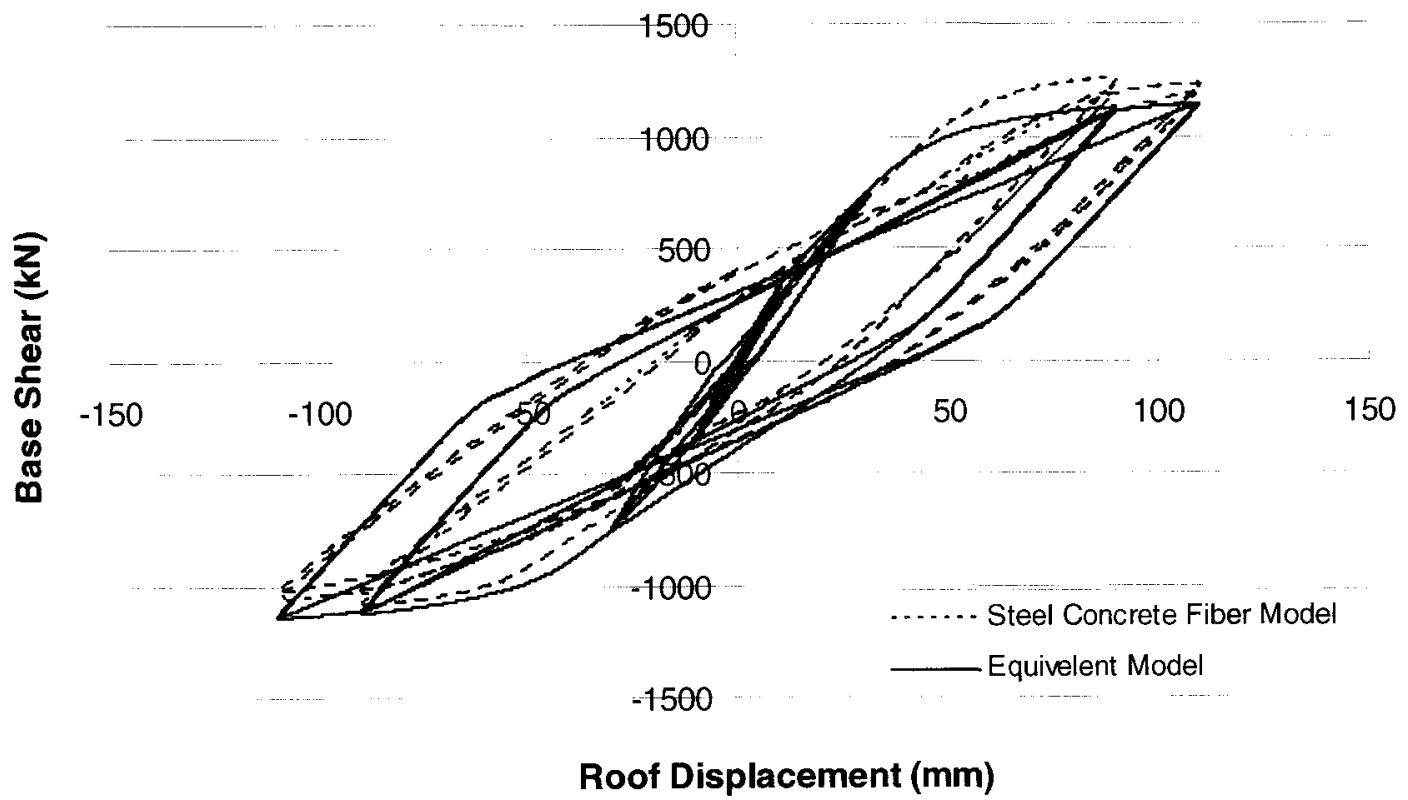

Figure 4-11 2-story 2-bay reinforced concrete frame cyclic loading simulation results 

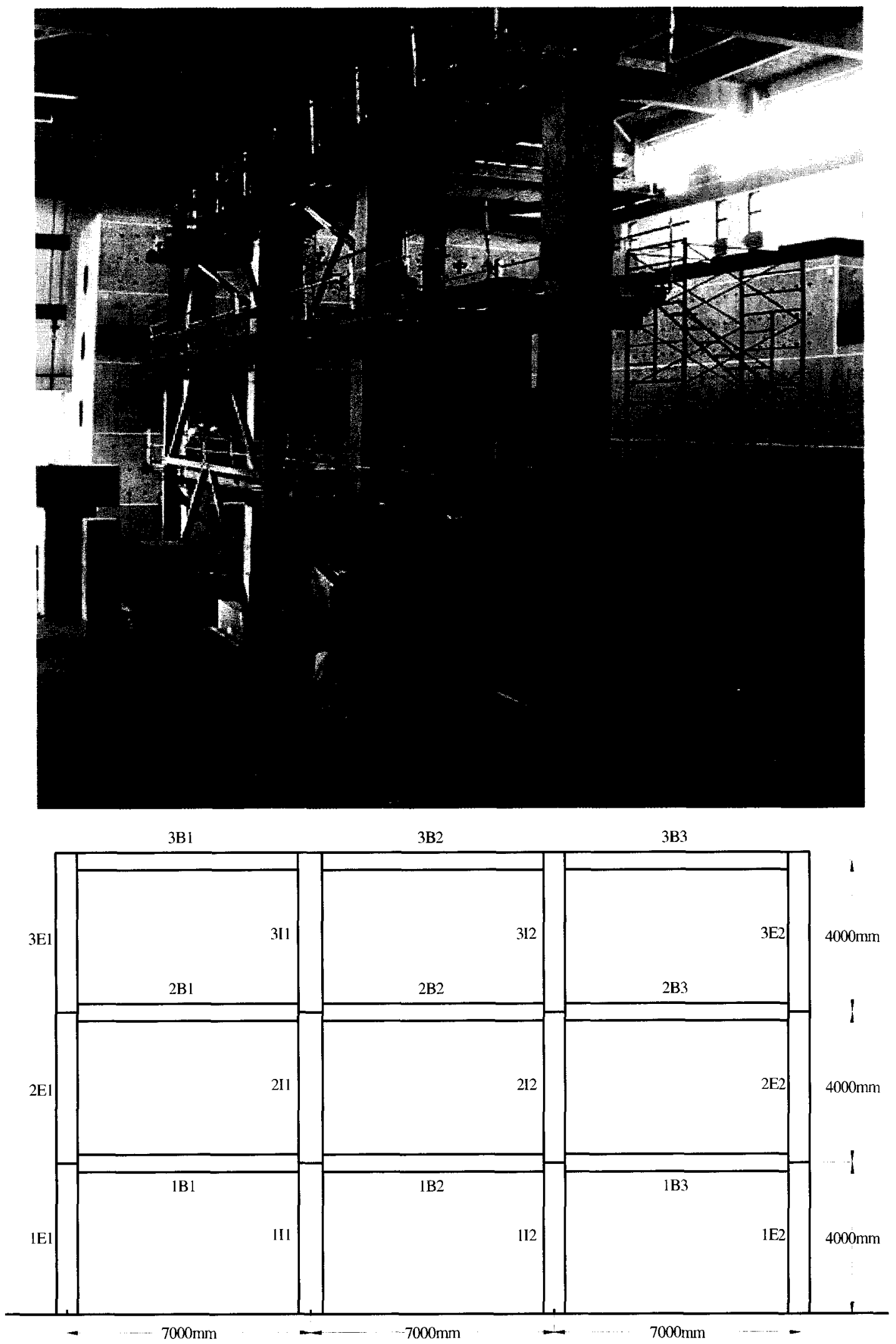

Figure 4-12 3-story 3-bay reinforced concrete-steel frame (NCREE) 


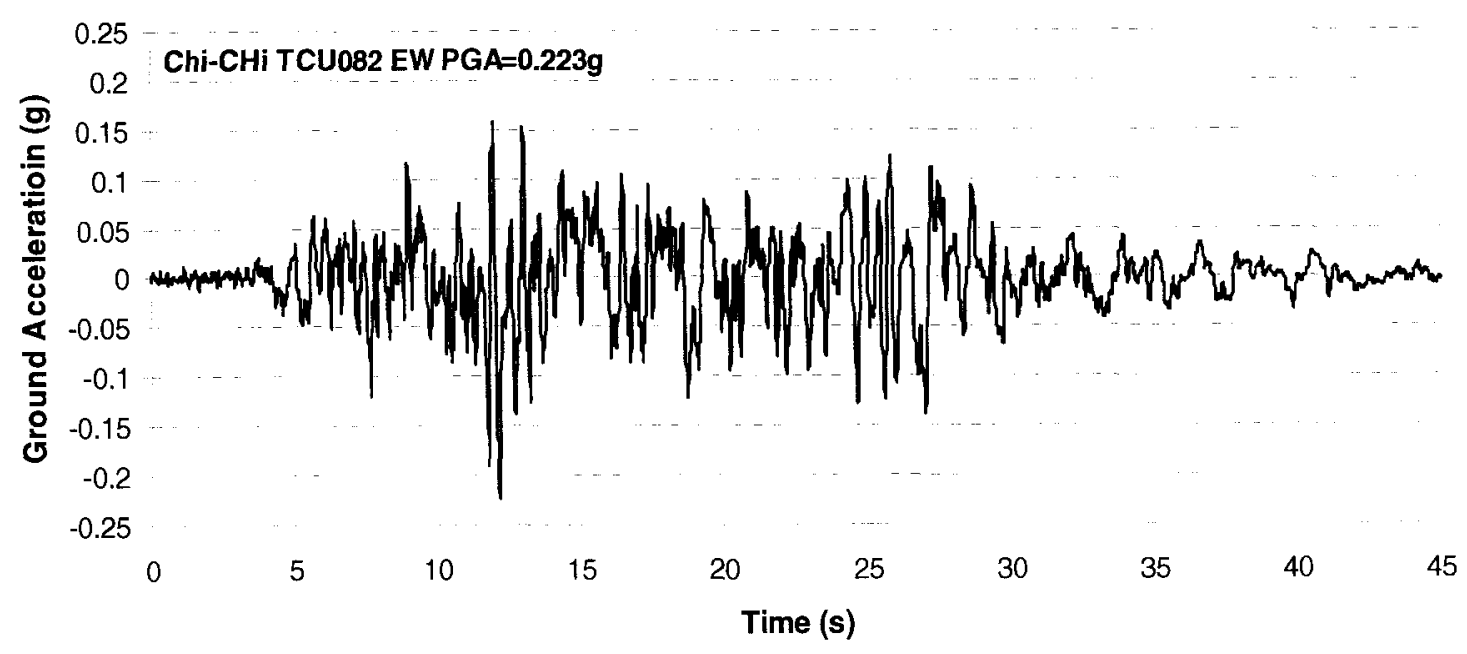

Figure 4-13 The original ground acceleration (before scaling) (PEER) 


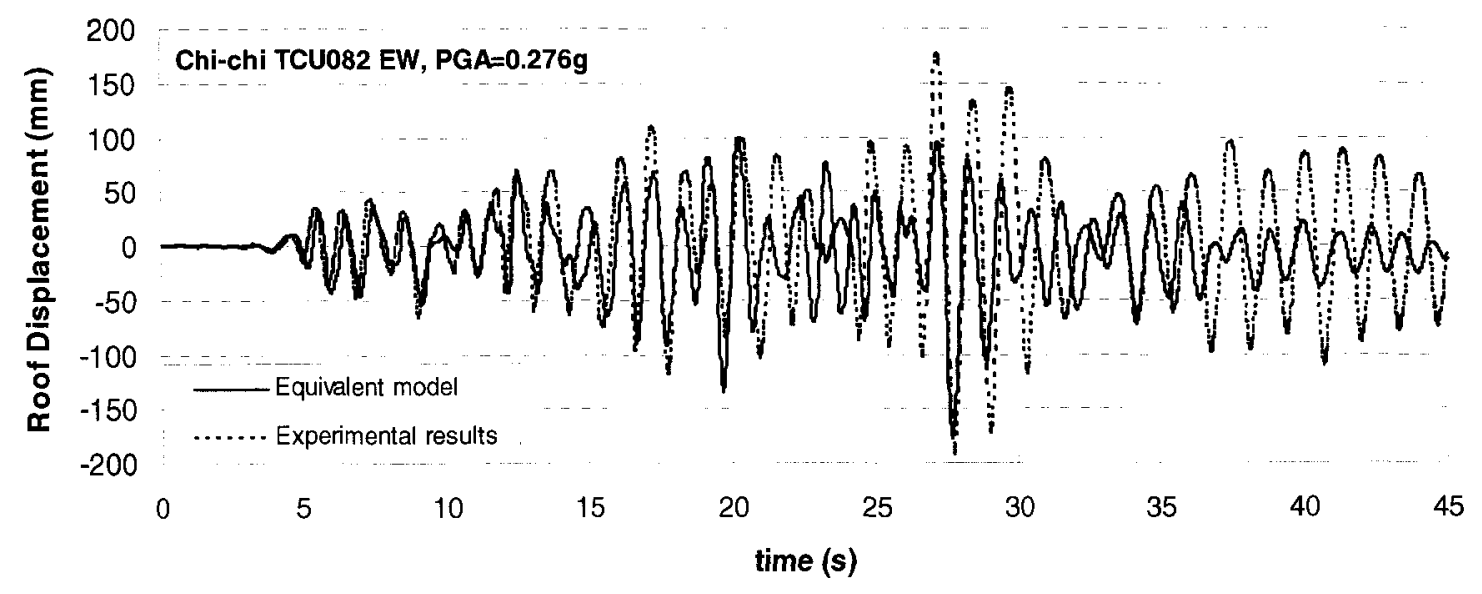

(a) Experimental results (Chen et al. 2003) and equivalent model

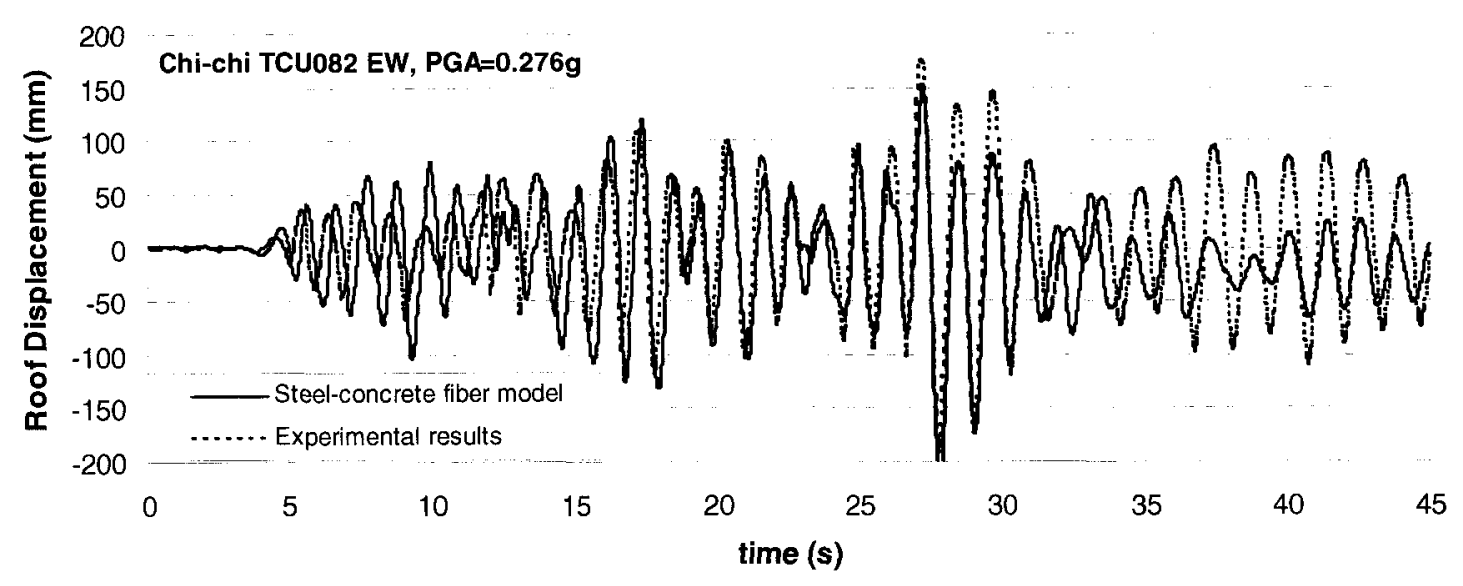

(b) Experimental results (Chen et al. 2003) and steel concrete model

Figure 4-14 3-story 3-bay frame roof displacement under Chi-chi TCU082 EW CC50/50 excitation 


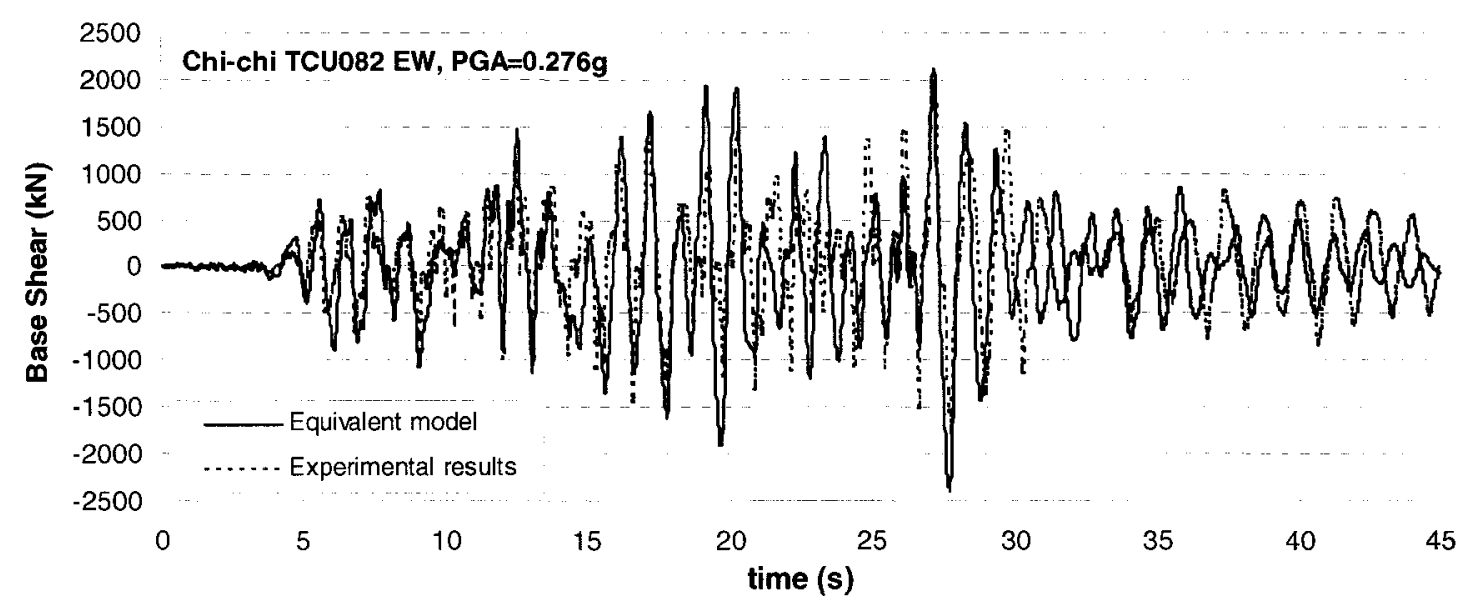

(a) Experimental results (Chen et al. 2003) and equivalent model

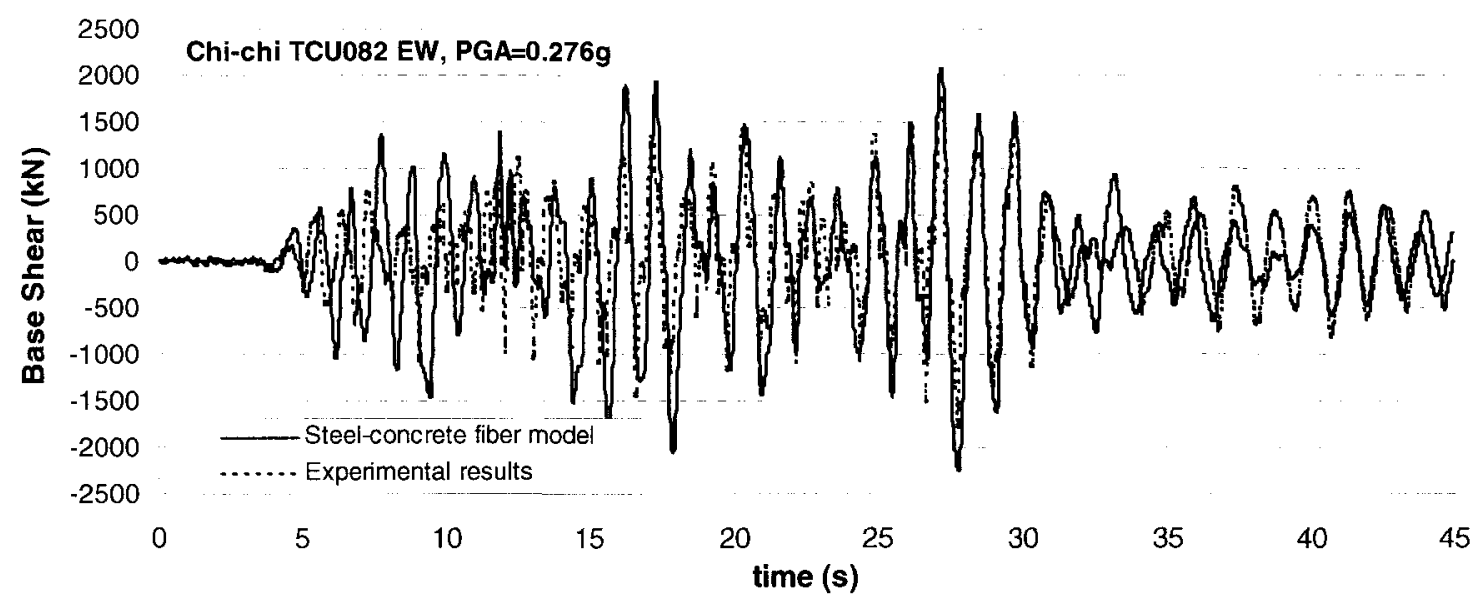

(b) Experimental results (Chen et al. 2003) and steel concrete model

Figure 4-15 3-story 3-bay frame base shear under Chi-chi TCU082 EW CC50/50 excitation 


\section{Chapter 5 Summary and Conclusions}

This thesis presents the derivation of a simplified modeling and analysis approach for the nonlinear analysis of reinforced structural members. In the simplified method, the original structural member section is modeled by an equivalent member section of homogeneous nonlinear material with a derived stress-strain relationship such that the equivalent section has the same moment-curvature behavior as the original reinforced concrete section. Numerical examples are presented to verify the procedures of the simplified analysis method and the derived equivalent model, which includes a reinforced concrete cantilever beam loaded an end moment, a double skinned concrete filled tubular (DSCFT) member subjected to a lateral load, a full-scaled 2-story and 2-bay reinforced concrete frame subjected to the lateral load and cyclic loading, and a full-scaled 3-story 3-bay composite RCS moment frame under earthquake excitation. Analytical results obtained from the simplified method are in good agreement with the analysis results obtained from the structural analysis software framework OpenSees and finite element program ABAQUS. The results also correlate well with experimental test results. The research shows that the nonlinear response of reinforced concrete members can be accurately predicted by the simplified method. The simplified method is an efficient tool for evaluating the nonlinear behavior of reinforced concrete structural members up to ultimate failure. The advantage of the simplified method is that it can be easily implemented with most structural analysis programs with the capabilities of user 
specified nonlinear material models. The developed model can accurately predict the nonlinear hysteretic responses of reinforced concrete and other reinforced concrete structures with frame members of arbitrary shapes and reinforcing details under severe earthquake excitations. 


\section{REFERENCES}

ABAQUS user manual. Version 6.3, Hobbit, Karlsson, and Sorensen Inc., Rhode Island, U.S.A, 2002.

Banon, H., Biggs, J.M., and Irvine, H. M. 1981. Seismic damage in reinforced concrete frames. Proceeding of the ASCE Journal of the Structural Division, 107(ST9): 17131729.

Chen, C.H., Lai, W.C., Cordova, P., Deierlein, G.G., Tsai, K.C. 2003. Pseudo-dynamic test of full-scale rcs frame: Part I - Design, construction, and testing”. Proceeding of the International Workshop on Steel and Concrete Composite Construction, Taipei, Taiwan. pp.107-118.

Clough, R.W., Benuska, K.L., and Wilson, E.L., 1965. Inelastic earthquake response of tall buildings. Proceeding of $3^{\text {rd }}$ World Conference on Earthquake Engineering, New Zealand, II, 68-89

Cook, R.D., Malkus, D.S., and Plesha, M.E., 1989. Concepts and applications of finite elements analysis. $3^{\text {rd }}$ Edition. John Wiley \& Sons, Inc. N.Y. USA.

Cordova, P., Chen, C.H., Deierlein, Lai, W.C., G.G., Tsai, K.C. 2003. Pseudo-dynamic test of full-scale rcs frame: Part II - Analysis and design implications. Proceeding of the International Workshop on Steel and Concrete Composite Construction, Taiwan. pp.118-131.

CSA. 1998. Design of concrete structures. Standard CSA A23.3. Canada Standard Association, Rexdale, Ont. 
D'Ambrisi, A. and Filippou, F.C. 1999. Modeling of cyclic shear behavior in RC members. ASCE Journal of Structural Division, 125(10): pp.1143-1150.

Deng, H.Z., Chang, Y.Y., Lau, D.T, Ostovari, S., and Tsai, K.C. 2003. A simplified approach for nonlinear response analysis of composite structural members. Proceedings of the International Workshop on Steel and Concrete Composite Construction, Taipei, Taiwan. pp.207-216.

Fillipou F.C., Popov E.P. and Bertero V.V. (1983), Modeling of R/C joint under cyclic excitations, ASCE Journal of the Structural Division, 109(11): 2666-2684.

Kent, D.C. and Park, R. 1971. Flexural members with confined concrete. Proceedings of the American Society of Civil Engineers Journal of Structural Division, 97(ST7): 1969-1990.

Kunnath, S.K., Reinhorn, A.M., and Park, Y.J. 1990. Analytical modeling of inelastic seismic response of r/c structures. ASCE Journal of the Structural Division, 116(4): 2257-2573.

Kwan, W.P., and Billington, S.L. 2001. Simulations of structural concrete under cyclic load. ASCE Journal of Structural Engineering, 127(12): 1391-1401.

Lee, T.K, and Pan, A.D.E. 2001. Analysis of composite beam-columns under lateral cyclic loading. ASCE Journal of Structural Engineering, 127(2): 186-193.

Lin, M.L. 2002. A study of double-skin concrete filled steel tubes under the combined axial and bending loads. Ph.D. Thesis, Department of Civil Engineering, National Taiwan University, Taipei, Taiwan.

Ma, S.M., Bertero, V.V. and Popov, E.P. 1976. Experimental and analytical studies on the hysteretic behavior of reinforced concrete rectangular and T-beams. EERC Report 
76-2. Earthquake Engineering Research Center, University of California, Berkeley, Calif.

Mazzoni, S., Mckenna, F., and Fenves, G.L. et al. 2005. OpenSees command Language manual. Release 1.6. Pacific Earthquake Engineering Research Centre, University of California, Berkeley, Calif.

Neuechofer, A. and Filippou, F.C. 1997. Evaluation nonlinear frame finite element models. ASCE Journal of the Structural Engineering, 123(7): 958-966.

Ozcebe, G. and Saatcioglu, M. 1987. Confinement of concrete columns for seismic loading. ACI Structural Journal, 84(4): 308-315.

Ozcebe, G. and Saatcioglu, M. 1989. Hysteretic shear model for reinforced concrete members. ASCE Journal of the Structural Engineering, 115(1): 132-148.

Park, Y.J., and Ang, A.H.S. 1985. Mechanistic seismic damage model for reinforced concrete. ASCE Journal of the Structural Engineering, 111(4): 722-739.

Park, R., Kent, D.C., and Sampson, R.A. 1972. Reinforced concrete members with cyclic loading. ASCE Journal of Structural Division, 98(7): 1341-1360.

Park, R., Priestley, M.J.N., and Gill, W.D. 1982. Ductility of square-confined concrete columns. ASCE Journal of Structural Engineering, 108(4): 929-950.

Popov, E.P., Bertero, V.V. and Krawinkler, H. 1972. Cyclic behavior of three r.c. flexural members with high shear. EERC Report 72-5, Earthquake Engineering Research Center. University of California, Berkeley, Calif.

Roufaiel, M.S.L., and Meyer, C. 1987. Analytical modeling of hysteretic behavior of r/c frames. ASCE Journal of the Structural Engineering, 113(3): 429-444. 
Saiidi, M., and Sozen, M.A. 1979. Simple and complex models for nonlinear seismic response of reinforced concrete structures. Structural Research Series 465, Civil Engineering Studies, University of Illinois, Urbana, I11.

Spacone, E., and EI-Tawil, S. 2004. Nonlinear analysis of steel-concrete composite structures: state of art. ASCE Journal of the Structural Engineering, 130(2): 159-168.

Takeda, T., Sozen, M.A., and Nielson, N.N. 1970. Reinforced concrete response to simulated earthquakes," Proceeding of the ASCE Journal of the Structural Division, 96(ST12): 2257-2573.

Tsai, K.C., Lin, M.L., Lin, Y.S., and Wang, T.F. 2002. Double skinned concrete filled tubes for bridge piers. Research Paper, National Taiwan University and Sinotech Engineering Consultant, Taipei, Taiwan. 